\title{
Argon tagging of doubly transition metal doped aluminum clusters: the importance of electronic shielding
}

\author{
Jan Vanbuel ${ }^{1}$, Piero Ferrari ${ }^{1}$, Meiye Jia ${ }^{1}$, André Fielicke ${ }^{2}$, Ewald Janssens ${ }^{1 *}$ \\ ${ }^{1}$ Quantum Solid-State Physics, KU Leuven, Celestijnenlaan 200D, 3001 Leuven, Belgium \\ ${ }^{2}$ Fritz-Haber-Institut der Max-Planck-Gesellschaft, Faradayweg 4-6, 14195 Berlin, Germany and \\ Institut für Optik und Atomare Physik, Technische Universität Berlin, Hardenbergstraße 36, 10623 Berlin, \\ Germany \\ *ewald.janssens@kuleuven.be
}

\begin{abstract}
The interaction of argon with doubly transition metal doped aluminum clusters, $\mathrm{Al}_{n} \mathrm{TM}_{2}{ }^{+}(n=1-18, \mathrm{TM}=\mathrm{V}, \mathrm{Nb}, \mathrm{Co}$, $\mathrm{Rh})$, is studied experimentally in the gas phase via mass spectrometry. Density functional theory calculations on selected sizes are used to understand the argon affinity of the clusters, which differ depending on the transition metal dopant. The analysis is focused on two pairs of consecutive sizes: $\mathrm{Al}_{6,7} \mathrm{~V}_{2}{ }^{+}$and $\mathrm{Al}_{4,5} \mathrm{Rh}_{2}{ }^{+}$, the largest of each pair showing a low affinity toward Ar. Another remarkable observation is a pronounced drop in reactivity at $n=14$, independent on the dopant element. Analysis of the cluster orbitals shows that this feature is not a consequence of cage formation but is electronic in nature. The mass spectra demonstrate a high similarity between the size-dependent reactivity of the clusters with $\mathrm{Ar}$ and $\mathrm{H}_{2}$. Orbital interactions provide an intuitive link between the two and further establish the importance of precursor states in the reactions of the clusters with hydrogen.
\end{abstract}




\section{Introduction}

The interaction of noble gases with clusters provides a rich, albeit indirect source of information on a variety of cluster properties. Foremost, the interaction is in most cases governed by weak charge-induced-dipole forces (adsorption energies $\mathrm{E}_{\mathrm{ads}} \approx 0.1-0.2 \mathrm{eV}$ ), which makes noble gases ideal messenger atoms for gas phase action spectroscopic techniques such as infrared multiple photon dissociation and vibrational predissociation spectroscopy [1, 2]. By virtue of the weakness of the interaction, the noble gas can be considered a spectator atom, with a negligible influence on the geometry and vibrational modes of the bare clusters [3]. Exceptions do exist, for which the presence of the $\operatorname{argon} \operatorname{tag}(\mathrm{s})$ should be explicitly taken into account to correctly interpret the infrared spectra and infer the cluster geometry $[4,5]$. For some small molecular complexes, which primarily involve transition metal or gold atoms, noble gases can form strong covalent bonds $\left(\mathrm{E}_{\mathrm{ads}} \approx 1 \mathrm{eV}\right)[6,7]$.

Besides their role as messengers in action spectroscopy, noble gases are also used in mass spectrometric studies as a structural probe. As transition metal atoms typically bind argon stronger than the atoms of main group elements do, argon tagging experiments elegantly demonstrated encaging of transition metal atoms in doped silicon and aluminum clusters $[8,9]$. Differences in propensity towards argon attachment depending on cluster dimensionality have also been exploited to titrate planar isomers out of a molecular beam of gold clusters [10].

Early experimental studies showed that (transition) metal cluster reactivity patterns towards closed-shell molecules, such as $\mathrm{H}_{2}, \mathrm{~N}_{2}$ and $\mathrm{CH}_{4}$, exhibit very similar features [11, 12, 13]. Moreover, for clusters of transition metals $\left(\mathrm{Co}_{n} \mathrm{Fe}_{n}\right.$, $\mathrm{Ni}_{n}, \mathrm{Nb}_{n}$ ), there is a strong correspondence between these reactivity patterns and the propensity of the clusters to form complexes with argon $[14,15]$. For hydrogen this correspondence can be explained by a two-step adsorption process. The first step involves a physisorbed hydrogen molecule in a precursor complex, which could explain the similarity with argon adsorption; the second step concerns the hydrogen dissociation. A stronger hydrogen physisorption in the first steps provides more time for the hydrogen molecule to probe the potential energy surface for a dissociative channel, and thereby a higher overall reaction rate [13].

Precursors are important in a variety of reactions, such as the activation of nitrogen on Fe(111) [16] and the dissociation of oxygen on $\operatorname{Pt}(111)$ [17]. They provide an explanation for the often observed but rather counterintuitive increase in reaction rate with decreasing temperature, similar to what is observed for ion-molecule reactions: the lifetime of the (weakly bound) precursor decreases with increasing temperature, or in other words, the adsorbent is more likely to desorb before the (dissociation) reaction occurs. Although precursors are a key ingredient in the field of reaction dynamics, such states are typically short-lived and therefore difficult to detect experimentally [18].

Several studies have alluded to the importance of a precursor state for the dissociative adsorption of hydrogen on transition metal clusters of, for example, iron and niobium, in order to explain the temperature-dependence of the experimentally determined reaction rates $[19,20]$. Similarly, the dehydrogenation of hydrocarbons by niobium clusters was hypothesized to be preceded by a strongly bound precursor complex [21]. The similar size-dependent interaction of $\mathrm{TM}_{n}(\mathrm{TM}=\mathrm{Co}, \mathrm{Fe}, \mathrm{Ni})$ with hydrogen and argon was explained by the higher polarizability of clusters with a smaller HOMO-LUMO gap [13]. Not only do clusters with a small HOMO-LUMO gap transfer more easily electrons to dissociate the hydrogen molecule, they also bind argon stronger due to a higher polarizability. For small aluminum clusters, $\mathrm{Al}_{n}(n=2-6)$, in contrast, calculations by Upton found no significant correlation between the HOMO-LUMO gaps and the reactivity towards hydrogen [22]. Orbital symmetry arguments, however, are more in line with the observed 
size-dependency of the reaction rates; the activation barrier seems to be dominated by Pauli repulsion between the $\sigma$ orbital of $\mathrm{H}_{2}$ and the cluster orbitals [23]. Similarly, no clear correlation between the ionization energy and the electron affinity with the reaction rate coefficients of $\mathrm{Al}_{n}$ Co clusters $(n=10,12,15)$ was found [24].

In this paper the interaction of argon with doubly transition metal doped aluminum clusters, $\mathrm{Al}_{n} \mathrm{TM}_{2}{ }^{+}(n=1-18 ; \mathrm{TM}$ $=\mathrm{V}, \mathrm{Nb}, \mathrm{Co}, \mathrm{Rh})$, is studied in the gas phase via mass spectrometry. Density functional theory calculations for selected species are used to rationalize the size-dependent fraction of argon-tagged clusters and their similarity to the reactivity patterns of $\mathrm{H}_{2}$. Analysis of electronic structure of these selected clusters shows that orbital interactions provide an intuitive link between the two and further establish the importance of a precursor state in the reaction with hydrogen.

\section{Materials and Methods}

\section{Experimental}

Doubly transition metal doped aluminum clusters $\mathrm{Al}_{n} \mathrm{TM}_{m}{ }^{+}(n=1-18 ; \mathrm{TM}=\mathrm{V}, \mathrm{Nb}, \mathrm{Co}, \mathrm{Rh})$ are produced by laser ablation in a dual-target dual-laser vaporization source, described in detail in Ref. [25]. To form the Ar complexes, $1 \%$ of $\mathrm{Ar}$ is mixed in the He carrier gas. By cooling the cluster source to a temperature of $110 \mathrm{~K}$, up to two Ar atoms could be attached to the $\mathrm{Al}_{n} \mathrm{TM}_{m}{ }^{+}$clusters. To form the hydrogenated complexes, in contrast, hydrogen gas was injected into the nozzle of the cluster source through a separate valve, at a backing pressure of 1 bar. After formation, the cluster beam is collimated by a $1 \mathrm{~mm}$ skimmer before it enters to a reflectron time-of-flight mass spectrometer.

\section{Computational}

Density function theory (DFT) calculations are performed with the Gaussian 09 software package [26], using the PBE functional [27]. This functional was shown to perform well to calculate properties of pure and doped aluminum clusters by comparison with CCSD simulations and experimental data [28]. For the $\mathrm{Al}_{n} \mathrm{~V}_{2}{ }^{+}$and $\mathrm{Al}_{n} \mathrm{Rh}_{2}{ }^{+}(n=1-12)$, the structures were taken from refs. [29, 30, 31]. In these earlier studies, extensive searches for low-energy isomers were conducted. $\mathrm{Al}_{n} \mathrm{TM}_{2}{ }^{+}(n=12-14 ; \mathrm{TM}=\mathrm{V}, \mathrm{Nb}, \mathrm{Co}, \mathrm{Rh})$ cluster and their Ar-tagged counterparts are studied for the first time and global optimizations were carried out the CALYPSO methodology [32]. The low-lying isomers were optimized for a range of possible spin multiplicities with the extensive Def2-TZVP basis set [33]. For the argon complexes $\mathrm{Al}_{4,5} \mathrm{Rh}_{2}{ }^{+} \cdot \mathrm{Ar}$ and $\mathrm{Al}_{6,7} \mathrm{~V}_{2}+\mathrm{Ar}$, Ar adsorption on different sites was considered. To calculate Ar adsorption energies at the PBE/Def2TZVP level, the D3 version of Grimme's dispersion corrections with Becke-Johnson damping (D3BJ) was used [34]. Wiberg bond indexes were computed in order to characterize the TM-TM and the $\mathrm{TM}_{2}-\mathrm{Al}_{n}{ }^{+}$interactions [35].

\section{Mass spectrometric results}

Mass spectra of the argon-tagged $\mathrm{Al}_{n} \mathrm{TM}_{2}{ }^{+}(\mathrm{TM}=\mathrm{V}, \mathrm{Rh}, \mathrm{Nb}, \mathrm{Co} ; n=1-18)$ clusters have been recorded. The spectra are complex, due to the presence of up to three dopant atoms and up to two argon tagging atoms. In order to facilitate the analysis of the size-dependent abundance of argon-complexes, the fractional distribution $F\left(\mathrm{Ar}_{p}\right)$ of formed complexes, defined as

$$
\left[F\left(\mathrm{Ar}_{p}\right)\right]=\frac{I\left(\mathrm{Al}_{n} \mathrm{TM}_{2} \mathrm{Ar}_{p}^{+}\right)}{\sum_{i=0}^{2} I\left(\mathrm{Al}_{n} \mathrm{TM}_{2} \mathrm{Ar}_{i}^{+}\right)}
$$


with $I\left(\mathrm{Al}_{n} \mathrm{TM}_{2} \mathrm{Ar}_{p}\right)$ the abundance of the cluster species in the mass spectrum, is extracted from the mass spectra and plotted in Figure 1. The mass spectra can be found in the supporting information. Singly doped $\mathrm{Al}_{n} \mathrm{TM}^{+}$clusters were also formed. However, the following analysis will focus on the double doped species. The main reasons for this selection are: 1 ) in $\mathrm{Al}_{n} \mathrm{TM}^{+}$clusters with $\mathrm{TM}=\mathrm{Co}$ and $\mathrm{Rh}$ argon complexes are hardly visible in mass spectra, and 2) correlations between $\mathrm{Ar}$ and $\mathrm{H}_{2}$ adsorption are less pronounced for the singly doped clusters. The fractional distribution of the $\mathrm{Al}_{n} \mathrm{TM}^{+}$ clusters is presented in the supporting information.

A great deal of similarity is noticeable between the argon affinity of $\mathrm{V}_{2}$ and $\mathrm{Nb}_{2}$ doped cationic aluminum clusters on the one hand, and the $\mathrm{Co}_{2}$ and $\mathrm{Rh}_{2}$ doped cationic aluminum clusters on the other hand. For $\mathrm{V}_{2}$ and $\mathrm{Nb}_{2}$ all clusters with $n<14$ have comparable amounts of one and two Ar atoms adsorbed (with the exception of $\mathrm{Al}_{7} \mathrm{~V}_{2}{ }^{+}$), while for $\mathrm{Co}_{2}$ and $\mathrm{Rh}_{2}$ doped $\mathrm{Al}_{n}{ }^{+}$clusters only the smaller $\left(n=1-7\right.$ for $\mathrm{Co}_{2}, n=1-4$ for $\mathrm{Rh}_{2}$ ) clusters have two Ar-tags that account for a fraction of at least $5 \%$. The argon affinity for both $\mathrm{Co}_{2}$ and $\mathrm{Rh}_{2}$ doped $\mathrm{Al}_{n}{ }^{+}$clusters increases again for $n=11-13$.

In our previous work on the interaction of doubly vanadium doped aluminum clusters with hydrogen [30], it was found that both vanadium atoms occupy a surface position for all calculated sizes $(n=1-12)$. The low coordination of both transition metals dopants could explain why a considerable fraction of the $\mathrm{Al}_{n} \mathrm{~V}_{2}{ }^{+}$clusters have two argon tags. If this line of reasoning is correct, also for $\mathrm{Al}_{n} \mathrm{Nb}_{2}{ }^{+}$both dopants should be located at the surface, while for $\mathrm{Al}_{n} \mathrm{Co}_{2}{ }^{+}$and $\mathrm{Al}_{n} \mathrm{Rh}_{2}{ }^{+}$ there should be a structural transformation in which both transition metal dopants gradually become inaccessible to the argon. For singly rhodium doped aluminum clusters, the calculated structures in ref. [36] indeed show that for $n>3$ and with the exception of $n=7$, the rhodium occupies an highly-coordinated position and is somehow geometrically shielded [9]. For the doubly doped clusters, however, for all calculated structures at least one of the rhodium atoms takes a surface position [31]. Thus, geometric shielding of the dopants does not seem to be the correct interpretation for the size dependent Ar adsorption in Figure 1. As will be discussed later, electronic instead of geometric shielding effects are more important to explain the observed trends.

A striking feature can be observed for all $\mathrm{Al}_{n} \mathrm{TM}_{2}{ }^{+}$clusters in Figure 1, for sizes $n>13$ there is, independent of the dopant element in question, a drastic decrease in the fraction of doubly doped aluminum clusters that form argon complexes. Although one could be tempted to attribute this decrease in Ar affinity to cage formation, i.e. the geometric shielding of the transition metals due to a structural transformation in which the dopant atom moves from a surface to an internal position, cfr. refs. [8,9], it seems counterintuitive that both dopants already occupy an internal position at smaller sizes as for a single dopant. For singly doped vanadium clusters, the critical size for encapsulation is $n=16$ [9, 37]. For example, experimental evidence for transition metal doped silicon clusters, $\mathrm{Si}_{n} \mathrm{TM}_{1,2}{ }^{+}(\mathrm{TM}=\mathrm{Ti}, \mathrm{V}, \mathrm{Cr}, \mathrm{Co})$, suggests that the onset of cage formation for two dopants occurs at sizes that are 6 to 7 atoms larger than the critical sizes for encapsulation of a single dopant [8]. 

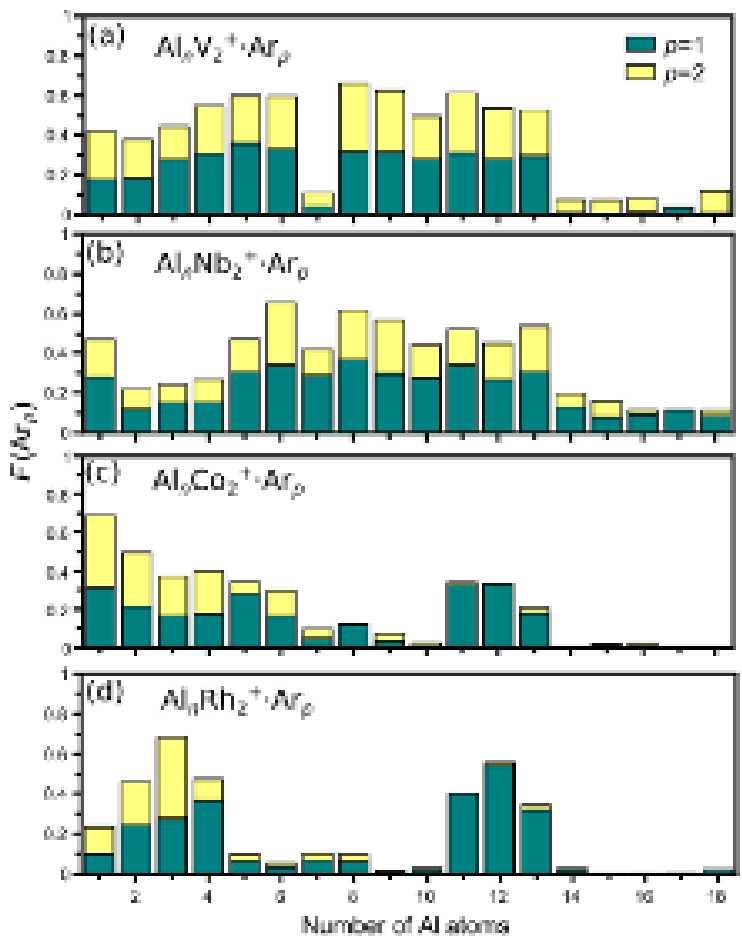

Figure 1. Fractional distribution of argon-tagged complexes with two a) vanadium, b) niobium, c) cobalt, and d) rhodium dopants. For sizes larger than $n=13$, the total fraction of argon-complexes decreases significantly, independent of the dopant element.

\section{Analysis and discussion}

\section{Ar-tagging of $\mathrm{Al}_{n} \mathrm{Rh}_{2}{ }^{+}$and $\mathrm{Al}_{n} \mathrm{~V}_{2}+(\mathrm{n}=1-14)$ clusters}

In Figure 2, the fractional distribution of Ar-tagged $\mathrm{Al}_{n} \mathrm{Rh}_{2}{ }^{+}$and $\mathrm{Al}_{n} \mathrm{~V}_{2}{ }^{+}(n=1-14)$ clusters is plotted above the inverse of the calculated distance between the two rhodium and two vanadium atoms in the clusters, $1 / d(\mathrm{TM}-\mathrm{TM})$. The TM-TM distances are taken from the lowest energy structures, which are plotted in the supporting information. As can be seen in the figure, there is a strong correlation between the two quantities for the $\mathrm{Rh}_{2}$ doped clusters (panels (a) and (b)).

The bonding between rare gases and transition metals is governed by a balance between strong but short-range Pauli repulsion and the weaker, long-range electrostatic forces. Intuitively, a larger $\mathrm{Rh}-\mathrm{Rh}$ interatomic distance implies decreased electronic charge density between the two Rh atoms (bonding state) and increased charge density at the periphery of $\mathrm{Rh}-\mathrm{Rh}$ (antibonding state). As the structures of the clusters indicate that both $\mathrm{Rh}$ atoms prefer highly coordinated positions, only the peripheral region is accessible to the argon. Increased electron density at the periphery facilitates a larger overlap with the argon orbitals, and results in stronger Pauli repulsion, pushing the argon atom further away from the cluster and reducing the electrostatic ion-induced dipole binding energy.

In contrast to $\mathrm{Al}_{n} \mathrm{Rh}_{2}{ }^{+}$, the correlation between the $\mathrm{V}-\mathrm{V}$ interatomic distance and the propensity for Ar attachment on $\mathrm{Al}_{n} \mathrm{~V}_{2}{ }^{+}$is not obvious (panels (c) and (d)). In particular the low argon affinity of $\mathrm{Al}_{7} \mathrm{~V}_{2}{ }^{+}$cannot be related to an enhanced $\mathrm{V}-\mathrm{V}$ distance. The lack of such correlation does not come as a big surprise, as the preceding analysis hinges on the fact that only the periphery of the TM-TM bond is accessible to the argon, whereas for the $\mathrm{V}_{2}$ doped aluminum clusters both 
vanadium atoms are at the cluster surface. This intuitive argument is made more comprehensible by means of two pairs of consecutive sizes: $\mathrm{Al}_{4,5} \mathrm{Rh}_{2}{ }^{+}$and $\mathrm{Al}_{6,7} \mathrm{~V}_{2}{ }^{+}$.

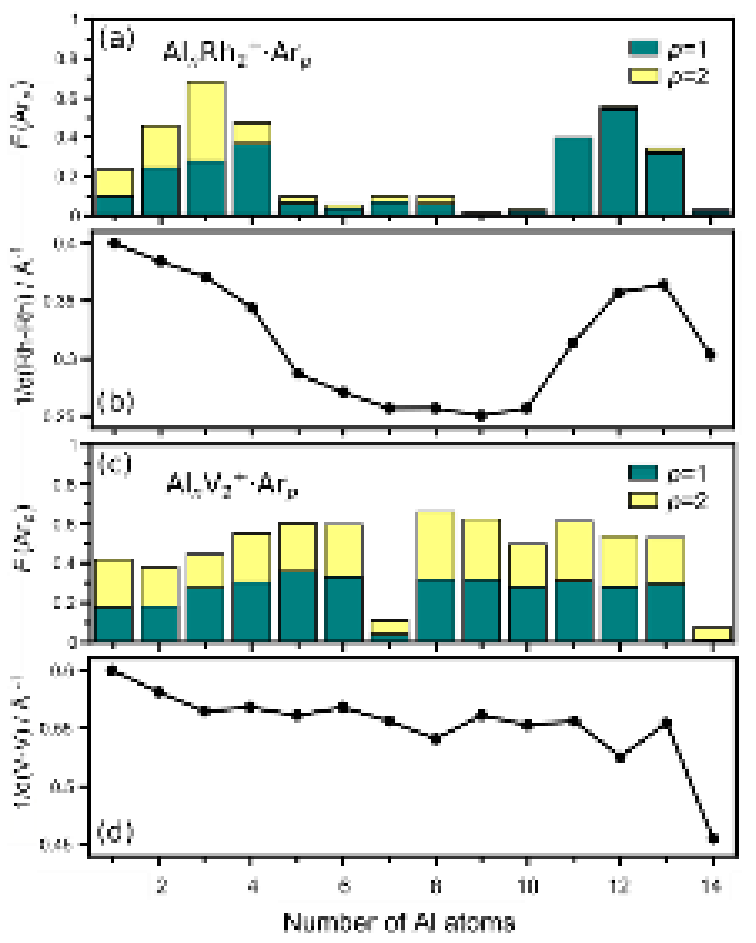

Figure 2. Comparison between the fractional distribution of $\mathrm{Ar}$-tagged (a) $\mathrm{Al}_{n} \mathrm{Rh}_{2}{ }^{+} \cdot \mathrm{Ar}_{p}$ and (c) $\mathrm{Al}_{n} \mathrm{~V}_{2}{ }^{+} \cdot \mathrm{Ar}_{p}$ clusters $(n=1-14, p=1$, 2 ), and the inverse distance between the two (b) rhodium and (d) vanadium atoms, $1 / d(T M-T M)$, in those clusters.

\section{Case study: $\mathrm{Al}_{4} \mathrm{Rh}_{2}{ }^{+}$and $\mathrm{Al}_{5} \mathrm{Rh}_{2}{ }^{+}$}

The sudden decrease in the fraction of Ar-tagged $\mathrm{Al}_{n} \mathrm{Rh}_{2}{ }^{+}$clusters and 1/d(Rh $\left.-\mathrm{Rh}\right)$ in going from size $n=4$ to $n=5$, motivates a detailed electronic structure analysis. In Figure $3 \mathrm{a}$, the structures of $\mathrm{Al}_{4} \mathrm{Rh}_{2}{ }^{+}$and $\mathrm{Al}_{5} \mathrm{Rh}_{2}{ }^{+}$are shown together with their Ar-tagged counterparts. As bond distances are governed by and sensitive to the distribution of electronic charge density, inspection of the molecular orbitals should be able to shed more light on the $20 \%$ increase of $d(\mathrm{Rh}-\mathrm{Rh})$, the $10 \%$ increase in the distance between $\mathrm{Ar}$ and the $\mathrm{Rh}$ atom to which it attaches $d(\mathrm{Ar}-\mathrm{Rh})$, and the concomitant decrease in $E_{B}(\mathrm{Ar})$ of about $50 \%$ from $n=4$ to $n=5$.

Figure $3 \mathrm{~b}$ shows selected frontier molecular orbitals of the Ar-tagged $\mathrm{Al}_{4} \mathrm{Rh}_{2}{ }^{+}$and $\mathrm{Al}_{5} \mathrm{Rh}_{2}{ }^{+}$that have electron density on both argon and the metal cluster. For $n=4$, which has a doublet spin state, the first (second) row shows the majority spin $\alpha$ (minority spin $\beta$ ) HOMO and HOMO-1. For $n=5$, which is a singlet, the HOMO, HOMO-1 and HOMO-2 orbitals are shown. All these orbitals have a node between the argon atom and the cluster, indicating that they are repulsive in nature and prevent the argon from further approaching the cluster. A second observation is that there is a clear difference between the two sizes with respect to the orientation of the argon valence p-orbitals relative to the Ar-Rh internuclear axis. For $\mathrm{Al}_{4} \mathrm{Rh}_{2}{ }^{+} \cdot(\mathrm{Ar})$, three of the four p-orbitals shown in Figure $3 \mathrm{~b}$ are oriented perpendicular to the internuclear axis, i.e. they are of $\pi^{*}$ symmetry. Only the majority spin HOMO has $\sigma^{*}$ symmetry with the Ar p-orbital oriented parallel to the internuclear axis. For $n=5$, the contributing Ar p-orbitals of HOMO-1 and HOMO-2 are oriented parallel to the Ar- 
$\mathrm{Rh}$ internuclear axis. As the orbital overlap in the $\sigma^{*}$ configuration is larger than in the $\pi^{*}$ orientation, the Pauli repulsion is larger; as a consequence, the $\mathrm{Ar}-\mathrm{Rh}$ interatomic distance is larger for $n=5$.

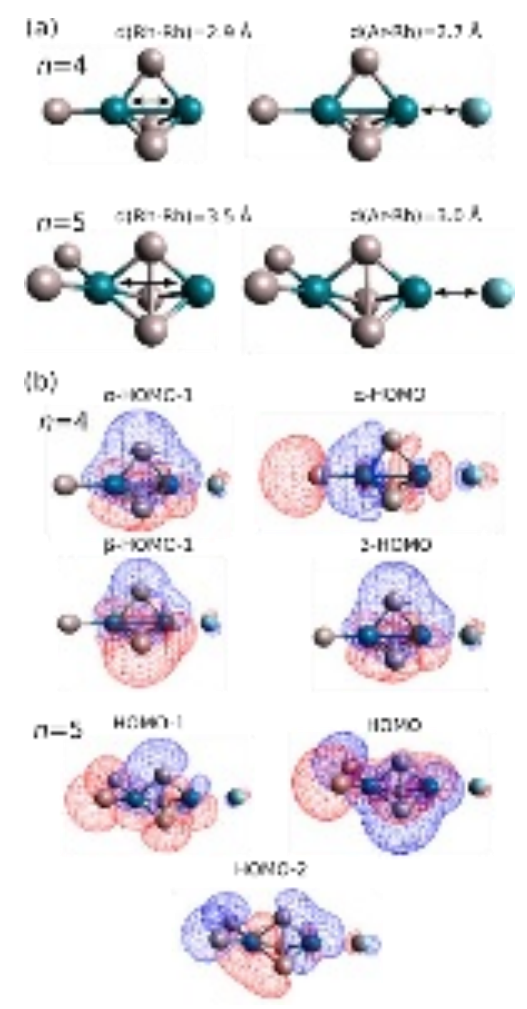

Figure 3. (a) The structures of $\mathrm{Al}_{4} \mathrm{Rh}_{2}{ }^{+}$and $\mathrm{Al}_{5} \mathrm{Rh}_{2}{ }^{+}$(left) together with their Ar-tagged counterparts (right). Aluminium atoms in grey, rhodium atoms in dark green, argon in cyan. (b) Selected molecular orbitals of $\mathrm{Al}_{4} \mathrm{Rh}_{2}{ }^{+} \cdot \mathrm{Ar}$ and $\mathrm{Al}_{5} \mathrm{Rh}_{2}{ }^{+} \cdot \mathrm{Ar}$. For $\mathrm{Al}_{4} \mathrm{Rh}_{2}{ }^{+} \cdot \mathrm{Ar}$, which is a doublet, spin up $(\alpha)$ and spin down $(\beta)$ orbitals are plotted. Isosurfaces are plotted for a density of $0.015 \mathrm{e} / \AA^{3}$.

A third observation, which ties the story of the correlation in Figure 2 together, is that the HOMO-1 and HOMO-2 orbitals of $\mathrm{Al}_{5} \mathrm{Rh}_{2}{ }^{+} \cdot(\mathrm{Ar})$, shown in Figure 3b, have a node between the two rhodium atoms. The HOMO-2 orbital mainly consists of the antisymmetric combination of rhodium $\mathrm{d}_{z^{2}}$ orbitals that hybridize with aluminum s- and p-orbitals. Such a bonding draws electronic density away from the bond center, towards the periphery of the internuclear $\mathrm{Rh}-\mathrm{Rh}$ axis. As a result, the $\mathrm{Rh}-\mathrm{Rh}$ bond strength decreases and the $\mathrm{Rh}-\mathrm{Rh}$ interatomic distance increases. The increased electron density at the periphery gives rise to additional Pauli repulsion, pushing the argon further away. The Ar binding energy therefore decreases, in agreement with the experimental fractional distribution in Figure 2a.

A similar kind of electronic shielding was observed for singly transition metal doped silicon clusters, $\mathrm{Si}_{n} \mathrm{TM}^{+}(n=5-$ $10, \mathrm{TM}=\mathrm{Cr}, \mathrm{Mn}, \mathrm{Cu}$ and $\mathrm{Zn}$ ), interacting with Ar [38], with the difference that for those silicon clusters the shielding was mainly due to s-electrons of the transition metal dopants, while here the shielding is caused by $\mathrm{Rh}_{z^{2}}$ orbitals.

\section{Case study: $\mathrm{Al}_{6} \mathrm{~V}_{2}{ }^{+}$and $\mathrm{Al}_{7} \mathrm{~V}_{2}+$}

To investigate the underlying reason for the abrupt decrease in argon affinity for the $\mathrm{V}_{2}$ doped clusters at $n=7$, the molecular orbitals of $\mathrm{Al}_{6} \mathrm{~V}_{2}{ }^{+}$and $\mathrm{Al}_{7} \mathrm{~V}_{2}{ }^{+}$are analyzed. The geometries of both clusters and the shapes of their HOMOs 
are shown in Figure 4. For $n=6$, which is open shell, both $\alpha$ and $\beta$ HOMOs are shown. Despite small differences in V$\mathrm{V}$ and $\mathrm{Ar}-\mathrm{V}$ bond lengths between $n=6$ and $n=7$, the mechanism described for $\mathrm{Al}_{4,5} \mathrm{Rh}_{2}{ }^{+}$is likely not the reason for the large difference in argon affinity. The orbitals on the right side of Figure 4, however, clearly show that the vanadium atoms of $\mathrm{Al}_{7} \mathrm{~V}_{2}{ }^{+}$are shielded by its $\mathrm{HOMO}$ orbital. For $\mathrm{Al}_{6} \mathrm{~V}_{2}{ }^{+}$, the vanadium atoms are more accessible, and the Ar-V repulsion is due to overlapping orbitals of $\pi^{*}$ symmetry. Analysis of Löwdin charges suggests significant electron transfer to the vanadium atoms for $n=7$ compared to $n=6$. While in $n=7$ the vanadium dopants have a partial charge of $-0.78 \mathrm{e}$, in $n=6$ the dopants only have $-0.16 \mathrm{e}$ (see supporting information).

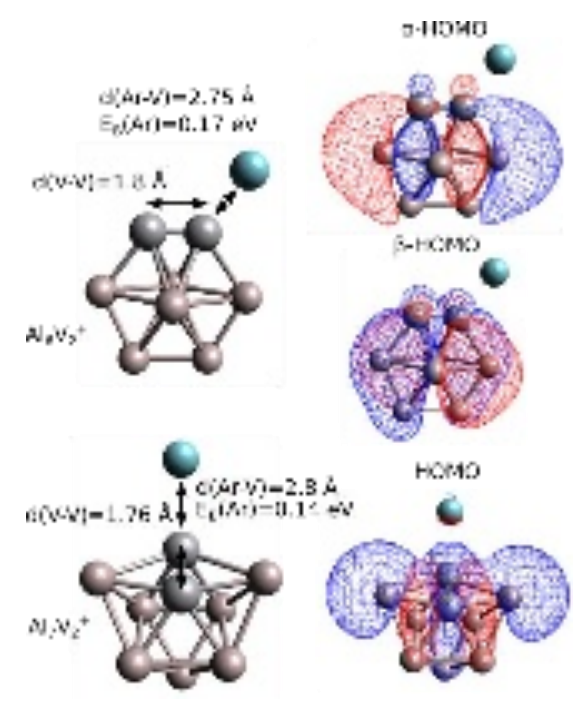

Figure 4. Geometries (left) and highest occupied molecular orbitals (HOMOs, right) of $\mathrm{Al}_{6} \mathrm{~V}_{2}{ }^{+} \cdot \mathrm{Ar}_{\text {and }} \mathrm{Al}_{7} \mathrm{~V}_{2}{ }^{+} \cdot \mathrm{Ar}$.

Such a charge transfer can significantly alter the electrostatic potential of the cluster, which in turn affects the induced dipole moment of the argon atom and hence its binding energy. The electrostatic potential of $\mathrm{Al}_{4} \mathrm{Rh}_{2}{ }^{+}, \mathrm{Al}_{5} \mathrm{Rh}_{2}{ }^{+}, \mathrm{Al}_{6} \mathrm{~V}_{2}{ }^{+}$ and $\mathrm{Al}_{7} \mathrm{~V}_{2}{ }^{+}$is plotted in Figure 5 on top of an iso-surface of electronic charge density $\left(\rho_{e}=0.001 e / a_{0}^{3}\right)$. The electrostatic potentials of $\mathrm{Al}_{4} \mathrm{Rh}_{2}{ }^{+}$and $\mathrm{Al}_{5} \mathrm{Rh}_{2}{ }^{+}$are quite similar, with a slightly lower potential at the less coordinated (more to the right in the figure) rhodium atom for $n=5$ compared to $n=4$. For the vanadium doped clusters, on the other hand, there is a clear difference between $n=6$ and $n=7$, with a more positive potential near the vanadium atoms for $\mathrm{Al}_{6} \mathrm{~V}_{2}{ }^{+}$. $\mathrm{Argon}$ binds stronger to cations than to anions, for atoms as well as clusters $[39,40]$. The lower argon affinity for anionic clusters has been attributed to electron 'spillout' [41, 42], and thus increased Pauli repulsion. The electrostatic potential is thus consistent with the stronger argon binding to $\mathrm{Al}_{6} \mathrm{~V}_{2}{ }^{+}$than to $\mathrm{Al}_{7} \mathrm{~V}_{2}{ }^{+}$. Note that, although the $\mathrm{Al}_{4} \mathrm{Rh}_{2}{ }^{+}$and $\mathrm{Al}_{5} \mathrm{Rh}_{2}^{+}$ electrostatic potentials are higher around the higher coordinated rhodium atom (more to the left in the figure), the DFT calculations clearly indicate that the argon preferably binds to the least coordinated rhodium atom. This again evidences the importance of Pauli repulsion: the charge density in-between the atoms derives from the aluminum $\mathrm{s}$ and $\mathrm{p}$ electrons, which have a stronger overlap with the argon valence orbitals and hence results in a larger repulsion.

The combined results of the case studies show that the relative contributions of Pauli repulsion and electrostatic attraction in the argon-cluster interaction is subtle. Both effects are not independent from one another. Therefore, the preceding analysis can be summarized as follows: increased electron charge density at the location of the transition metal 
dopants lowers the electrostatic potential and at the same time increases Pauli repulsion, resulting in a lowering of the binding energy of the argon atom and decreasing the abundance of the argon-tagged species in the mass spectra.

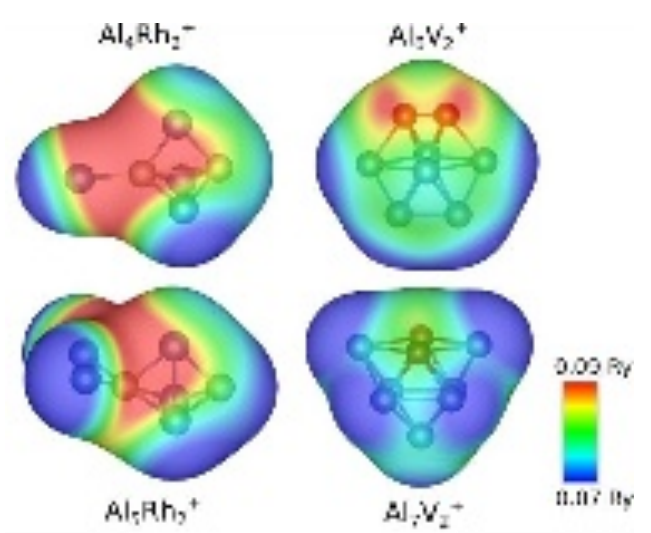

Figure 5. Electrostatic potentials of $\mathrm{Al}_{4} \mathrm{Rh}_{2}{ }^{+}, \mathrm{Al}_{5} \mathrm{Rh}_{2}{ }^{+}$(left), $\mathrm{Al}_{6} \mathrm{~V}_{2}{ }^{+}$and $\mathrm{Al}_{7} \mathrm{~V}_{2}{ }^{+}$(right) on top of an isosurface of the electronic charge density $\left(\rho_{e}=0.001 e / a_{0}^{3}\right)$.

\section{Analysis of $\mathrm{Al}_{n} \mathrm{TM}_{2}{ }^{+}(n=12,13,14 ; \mathrm{TM}=\mathrm{V}, \mathrm{Nb}, \mathrm{Co}, \mathrm{Rh})$}

The calculated structures of the lowest energy isomers of $\mathrm{Al}_{12-14} \mathrm{TM}_{2}^{+}(\mathrm{TM}=\mathrm{V}, \mathrm{Nb}, \mathrm{Co}, \mathrm{Rh})$ are shown in Figure 6 . While for the rhodium and cobalt doped clusters, one of the dopants assumes an internal position, both transition metals remain at the surface for the vanadium and niobium doped clusters, with the exception of $\mathrm{Al}_{14} \mathrm{~V}_{2}{ }^{+}$. As anticipated, encapsulation is not the explanation for the observed decrease in argon affinity for the larger sizes: none of the $\mathrm{Al}_{14} \mathrm{TM}_{2}{ }^{+}$ aluminum frameworks encapsulates both dopants. There must be another reason for the observed decrease in the abundance of the argon-tagged clusters for $n>13$ in Figure 1.

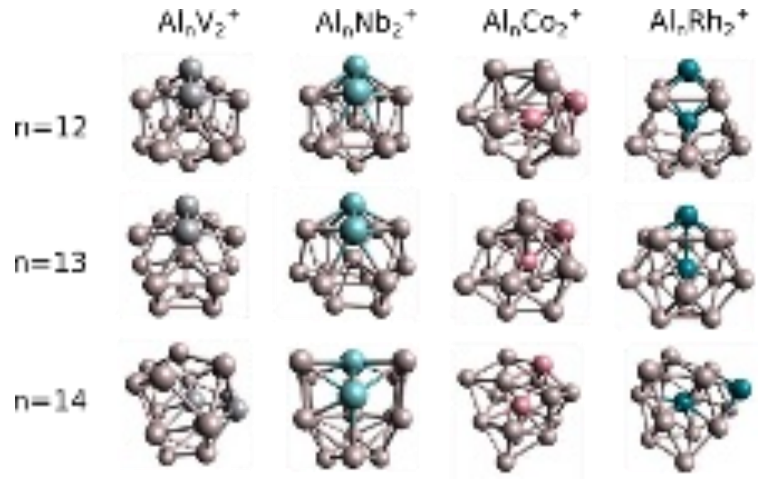

Figure 6. Lowest energy isomers of Ar-tagged $\mathrm{Al}_{14} \mathrm{TM}_{2}{ }^{+}(\mathrm{TM}=\mathrm{V}, \mathrm{Nb}, \mathrm{Co}, \mathrm{Rh})$ clusters. For all sizes, at least one of the dopant atoms occupies a surface position. 


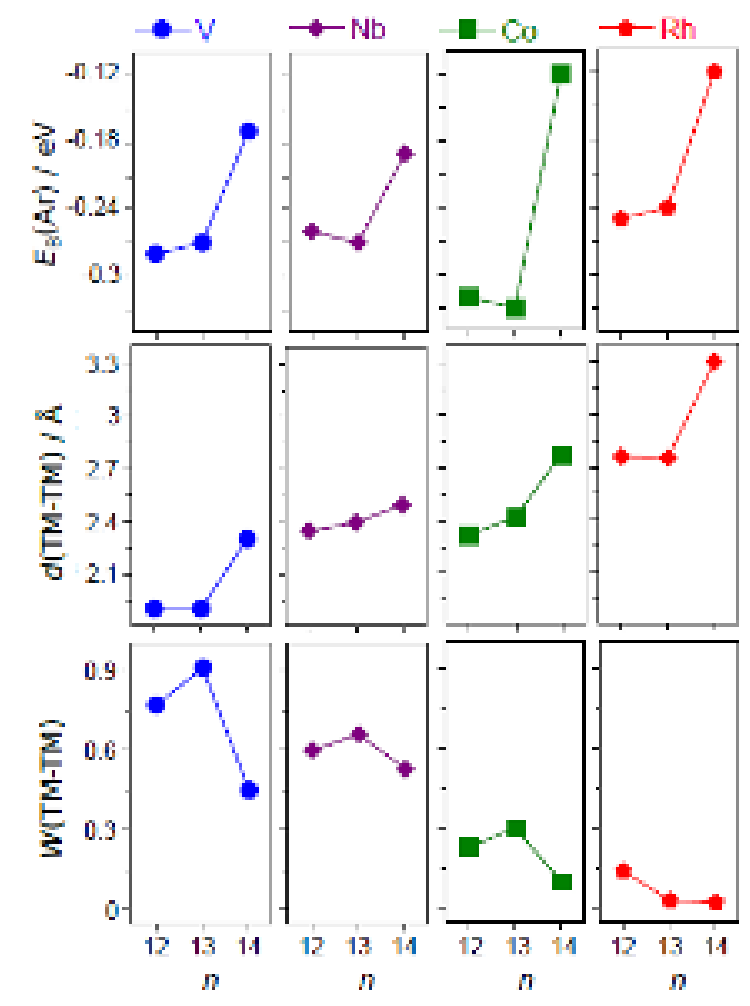

Figure 7. Calculated properties of $\mathrm{Al}_{12-14} \mathrm{TM}_{2}{ }^{+}(\mathrm{TM}=\mathrm{V}, \mathrm{Nb}, \mathrm{Co}, \mathrm{Rh})$ clusters. First row: argon binding energy, $E_{\mathrm{B}}(\mathrm{Ar})$. Second row: distance between the two transition metals, $d(\mathrm{TM}-\mathrm{TM})$. Third row: Wiberg bond index of the TM-TM interaction, W(TM-TM).

To investigate the hypothesis of electronic shielding, i.e. that unfavorable overlap of electronic orbitals increases Pauli repulsion and decreases the binding energy, each of the structures in Figure 6 was reoptimized after adding an argon atom. In all $\mathrm{Al}_{12-14} \mathrm{TM}_{2}{ }^{+}$clusters argon was found to bind stronger to the least coordinated transition metal atom. The calculated binding energies $E_{\mathrm{B}}(\mathrm{Ar})$ are plotted in the top row of Figure 7. The calculations predict for all TM dopants a larger binding energy (more negative) for $n=12$ and 13 as compared to $n=14$, consistent with a higher abundance of the argon-complexes. The second row of Figure 7 presents the interatomic $d(\mathrm{TM}-\mathrm{TM})$ distances. A distinct correlation between the bond distance and the argon binding energy can be seen. Correlation, however, does not imply causation; both quantities could be brought about by another underlying, intrinsic property of the cluster. Moreover, the fact that the decrease in $E_{B}(\mathrm{Ar})$ and increase in $d(\mathrm{TM}-\mathrm{TM})$ occurs independently for each of the four transition metals, strongly suggests that the underlying cause is related to the aluminum host. Wiberg bond indexes $(W)$ were computed for the clusters. The third row of Figure 7 present the TM-TM bond indexes. Although not perfect, a correlation between $d$ (TM$\mathrm{TM})$ and $\mathrm{W}(\mathrm{TM}-\mathrm{TM})$ is observed, with shorter TM-TM interatomic distances corresponding to a higher bond order.

These observations ask for a closer examination of the electronic structure of the clusters. For $n=13$, the orbital overlap between argon and the cluster is of $\pi^{*}$ symmetry, whereas for $n=14$, all occupied frontier orbitals with electron density on both Ar and the TM dopants are of $\sigma^{*}$ symmetry. Plots of the relevant molecular orbitals for $n=13$ and $n=14$ are presented in Figure 8. 


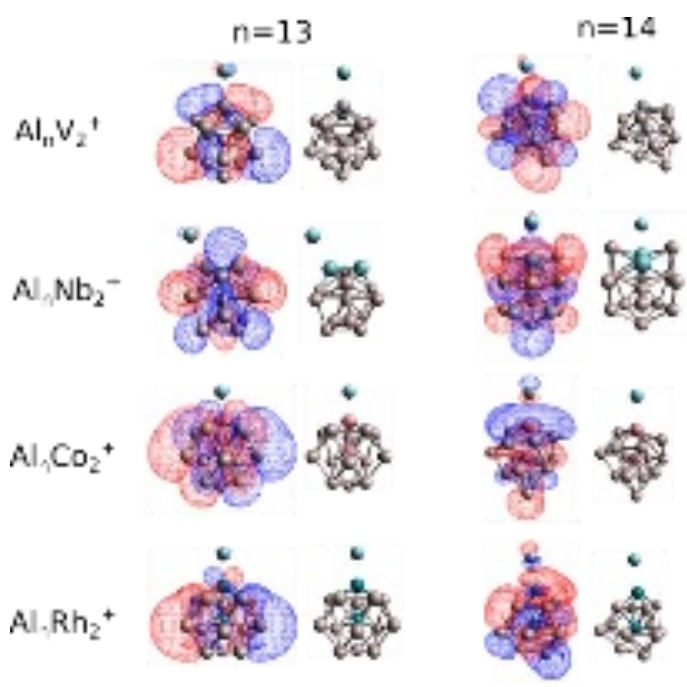

Figure 8. Occupied frontier orbitals with electron density on both $\mathrm{Ar}$ and the $\mathrm{TM}_{\mathrm{M}} \mathrm{Al}_{n} \mathrm{TM}_{2}{ }^{+}(n=13,14 ; \mathrm{TM}=\mathrm{V}, \mathrm{Nb}, \mathrm{Co}, \mathrm{Rh})$. On the side of each molecular orbital plot, the cluster geometry is presented.

While the frontier orbitals explain why the Ar binding energy is lower for $n=14$ as for $n=13$, they do neither explain why the decreased Ar affinity occurs exactly at this size, nor why the transition size is independent of the kind of TM dopants. One pertinent question remains, namely what is the role of the aluminum framework in the observed reactivity pattern? The striking feature that for all dopants the abundance of argon-tagged clusters decreases at $n=14$, which is a magic size of cationic aluminum clusters [43], is an indication for an electronic shell structure effect. However, four factors render electron counting and shell structure identification in transition metal doped aluminum clusters non-trivial. The first is that the number of valence electrons of transition metals that delocalize depends on size and structure [44]. The second factor is that not only transition metals, but also aluminum can exhibit mixed valence [45]. A third factor is that the nuclear charge of the aluminum atoms is not well screened, and so the ionic background plays a larger role [46]. Finally, the fourth factor is that the ionic background potential is disturbed by the presence of heteroatom dopants [47]. The orbitals of $n=13$ and 14 in Figure 8 indicate that the HOMO orbitals of the rhodium and cobalt doped aluminum clusters resemble $2 \mathrm{P}$ states of the spherical jellium model. As the $2 \mathrm{P}$ shells are more sensitive to the potential background in the interior of the cluster, the filling of the $2 \mathrm{P}$ shells might explain why the two rhodium atoms approach each other after $n=10$; one rhodium atom is "pulled" inside, thereby lowering the energy of the 2P orbitals [47]. The HOMO of $\mathrm{Al}_{13} \mathrm{~V}_{2}{ }^{+}$resembles a $2 \mathrm{P}$ jellium orbital as well. The HOMO of $n=14$, on the other hand, is resembling a $1 \mathrm{G}$ jellium orbital, indicating a shell closure between $n=13$ and $n=14$.

\section{Similar reactivity pattern of $\mathrm{Al}_{n} \mathrm{Rh}_{2}{ }^{+}$and $\mathrm{Al}_{n} \mathrm{~V}_{2}{ }^{+}$towards $\mathrm{H}_{2}$ and Ar: precursor state}

Figure 9 shows the fractional distribution of the argon-tagged (panels (a) and (c)) and hydrogenated (panels (b) and (d)) doubly rhodium and vanadium doped aluminum clusters. Although there is not a one-to-one correspondence, the reactivity pattern of $\mathrm{Al}_{n} \mathrm{Rh}_{2}{ }^{+}$towards hydrogen and the trends in their propensity to form argon-complexes are very similar: $\mathrm{Al}_{1-4} \mathrm{Rh}_{2}{ }^{+}$and $\mathrm{Al}_{11-13} \mathrm{Rh}_{2}{ }^{+}$clusters readily form argon and hydrogen complexes, whereas other sizes do not. Exceptions are $\mathrm{Al}_{7} \mathrm{Rh}_{2}{ }^{+}$and $\mathrm{Al}_{14} \mathrm{Rh}_{2}{ }^{+}$, which do not attach any argon but are reactive towards hydrogen. 
For the $\mathrm{V}_{2}$ doped aluminum clusters, a less pronounced but nevertheless similar size-to-size variation can be discerned. Up to $n=13$ all clusters can be tagged with one and even two argon atoms, except for $\mathrm{Al}_{7} \mathrm{~V}_{2}{ }^{+}$which is also unreactive towards hydrogen. $\mathrm{Al}_{4} \mathrm{~V}_{2}{ }^{+}$and $\mathrm{Al}_{5} \mathrm{~V}_{2}{ }^{+}$, in contrast, do adsorb argon but barely any hydrogen. For sizes larger than $n=13$ there is a sudden decrease in the fractional distribution for Ar adsorption, which, as argued before, is due to electronic shielding. Similarly, there is a gradual decrease in the reactivity of the $\mathrm{Al}_{n} \mathrm{~V}_{2}{ }^{+}$clusters towards hydrogen for $n>13$. It was already noted in earlier work that for $n=14$ and $n=15$ an equal amount of one and two hydrogen molecules were adsorbed onto the cluster, whereas most other $\mathrm{Al}_{n} \mathrm{~V}_{2}{ }^{+}$clusters only adsorb a single $\mathrm{H}_{2}$ [30].

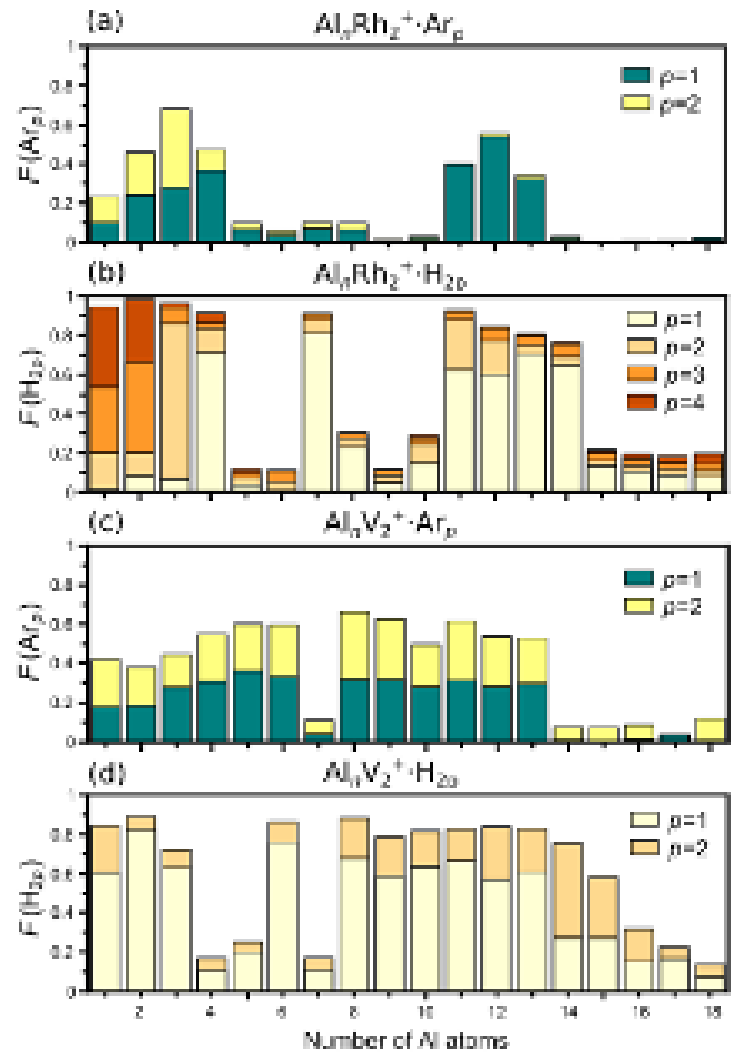

Figure 9. Fractional distribution of $\mathrm{Ar}$ (a) and hydrogen (b) complexes of $\mathrm{Al}_{n} \mathrm{Rh}_{2}{ }^{+}(n=1-18)$ clusters. Fractional distribution of $\mathrm{Ar}$ (c) and hydrogen (d) complexes of $\mathrm{Al}_{n} \mathrm{~V}_{2}+(n=1-18)$ clusters.

In previous works, the importance of a possible precursor state in the hydrogenation reaction mechanism of doped aluminum clusters was discussed [36, 30, 29]. The main argument that lead to this interpretation is the correlation of calculated molecular hydrogen adsorption energies, $\mathrm{H}-\mathrm{H}$ distances in the molecularly adsorbed complexes, and the abundance of the hydrogenated clusters. Although for the smallest singly rhodium doped clusters $(n<4)$ and larger doubly doped rhodium clusters $(n=12,13)$ the infrared multiple photon dissociation spectra indicated that the hydrogen adsorbs molecularly on the dopant atom in a side-on configuration $[29,36]$, for other abundant hydrogenated complexes, e.g. $\mathrm{Al}_{7} \mathrm{RhH}_{2}{ }^{+}, \mathrm{Al}_{11} \mathrm{Rh}_{2} \mathrm{H}_{2}{ }^{+}$and the vanadium doped aluminum clusters, the infrared absorption bands were assigned to the vibrational modes of single hydrogen atoms at different sites. DFT calculations also predict that dissociative adsorption for these clusters is energetically preferred. Therefore, the formation and stability of the molecularly adsorbed complex seems rate-limiting for the dissociative adsorption of hydrogen, or in other words, the reaction likely proceeds via a precursor state. Based on this argument and the analysis of the interaction of argon with the doubly transition metal doped clusters, the similarity between the propensity to adsorb hydrogen and argon can be due to two related reasons. 
Firstly, the HOMOs that result in less shielding of the transition metal atoms, i.e. those that exhibit locally $\pi$-symmetry are also less repulsive for the $\sigma$ orbital of $\mathrm{H}_{2}$. Additionally, these orbitals overlap with the anti-bonding $\sigma^{*}$-orbital of hydrogen and therefore activate $\mathrm{H}_{2}$ and lead to the formation of a Kubas-complex and/or dissociative adsorption of hydrogen. The correlation, however, is not one-to-one; there are clear differences between the hydrogen reactivity and argon affinity patterns in Figure 9 (e.g. for clusters $\mathrm{Al}_{1-3} \mathrm{Rh}^{+}, \mathrm{Al}_{7} \mathrm{Rh}_{2}{ }^{+}, \mathrm{Al}_{4,5} \mathrm{~V}_{2}{ }^{+}$and the larger vanadium doped clusters). These differences, however, are not surprising; even though the $\mathrm{H}_{2}$ adsorption on the clusters is strongly influenced by a precursor state in which hydrogen is adsorbed molecularly, it is also dependent on the subsequent dissociation of $\mathrm{H}_{2}$. This additional step is evidently absent when the clusters interact with Ar.

\section{Conclusions}

In summary, the interaction of argon with doubly transition metal doped aluminum clusters, $\mathrm{Al}_{n} \mathrm{TM}_{2}^{+}(n=1-18, \mathrm{TM}=$ $\mathrm{V}, \mathrm{Nb}, \mathrm{Co}, \mathrm{Rh}$ ), was studied experimentally in the gas phase via mass spectrometry. Selected sizes were analysed computationally using density functional theory calculations. Although the argon affinity of the clusters is size- and dopant-dependent, there is a similarity between $\mathrm{V}$ and $\mathrm{Nb}$ on the one hand, and $\mathrm{Co}$ and $\mathrm{Rh}$ on the other. A detailed analysis of the rhodium and vanadium doped aluminum cluster electronic structure shows that the abundance of argoncluster complexes in the mass spectra is sensitive to electronic shielding of the transition metal dopants. For Rh, the distance between the two transition metals is indicative of the charge density location along the internuclear axis (center vs. periphery) and hence presence or absence of shielding. For the doubly vanadium doped aluminum clusters, both transition metals bind at the surface and the TM-TM distance is less sensitive to charge transfer. The argon affinity for all $\mathrm{Al}_{n} \mathrm{TM}_{2}{ }^{+}(\mathrm{TM}=\mathrm{V}, \mathrm{Nb}, \mathrm{Co}, \mathrm{Rh})$ clusters decreases abruptly at $n=14$, which seems to be related to electronic shell closings and not to encapsulation of the TM atoms.

Finally, the similarity between the fractional distribution of argon-cluster complexes and hydrogenated clusters is proposed to be related to the presence of a precursor state on the PES of the cluster-hydrogen reaction: HOMOs that result in less shielding of the transition metal atoms from argon are also less repulsive towards the $\sigma$ orbital of $\mathrm{H}_{2}$. Secondly, due to their overlap with the anti-bonding $\sigma^{*}$ orbital of hydrogen, these orbitals lead to the stabilization of a Kubas-complex and/or dissociative adsorption of hydrogen.

\section{Supplementary Material}

The supplementary material includes (i) representative mass spectra, (ii) the calculated lowest-energy structures of $\mathrm{Al}_{n} \mathrm{~V}_{2}{ }^{+}$ and $\mathrm{Al}_{n} \mathrm{Rh}_{2}{ }^{+}(n=2-14)$ clusters, (iii) mass spectrometric fractions of $\mathrm{Ar}$ and $\mathrm{H}_{2}$ on cationic single $\mathrm{V}$ and $\mathrm{Rh}$ doped clusters, and (iv) a partial charge analysis of selected clusters.

\section{Acknowledgements}

This work has been supported by the KU Leuven Research Council (project C14/18/073) and by the Research Foundation - Flanders (FWO, project G0A05.19N). J.V. and P.F. are grateful to the FWO for a PhD Fellowship and Postdoctoral grant, respectively. 


\section{Data availability}

The data that supports the findings of this study are available from the corresponding author upon reasonable request.

\section{References}

[1] K. R. Asmis, M. Brümmer, C. Kaposta, G. Santambrogio, G. von Helden, G. Meijer, K. Rademann and L. Wöste, Phys. Chem. Chem. Phys. 4, 1101 (2002).

[2] J. Oomens, B. G. Sartakov, G. Meijer and G. Helden, Int. J. Mass Spectrom. 254, 1 (2006).

[3] P. Gruene, D. M. Rayner, B. Redlich, A. F. G. van der Meer, J. T. Lyon, G. Meijer and A. Fielicke, Science 321, 674 (2008).

[4] R. Gehrke, P. Gruene, A. Fielicke, G. Meijer and K. Reuter, J. Chem. Phys. 130, 034306 (2009).

[5] A. Shayeghi, R. L. Johnston, D. M. Rayner, R. Schfer and A. Fielicke, Angew. Chem. Int. Ed. 54, 10675 (2015).

[6] S. Pan, G. Jana, B. Merino and P. K. Chattaraj, ChemistryOpen 8, 173 (2019).

[7] L. Belpassi, I. Infante, F. Tarantelli and L. Visscher, J. Am. Chem. Soc. 1303, 1048 (2008).

[8] E. Janssens, P. Gruene, G. Meijer, L. Wöste, P. Lievens and A. Fielicke, Phys. Rev. Lett. 99, 063401 (2007).

[9] S. M. Lang, P. Claes, S. Neukermans and E. Janssens, J. Am. Soc. Mass Spectrom. 22, 1508 (2011).

[10] W. Huang and L.-S. Wang, Phys. Rev. Lett. 102, 153401 (2009).

[11] A. Nakajima, T. Kishi, Y. Sone, N. S. and K. Kaya, Z. Phys. D 19, 385 (1991).

[12] D. M. Cox, D. J. Trevor, R. L. Whetten and A. Kaldor, J. Phys. Chem. 92, 421 (1988).

[13] M. B. Knickelbein, Annu. Rev. Phys. Chem. 50, 79 (1999).

[14] M. B. Knickelbein and W. J. C. Menezes, Chem. Phys. Lett. 184, 433-438, 1991.

[15] M. B. Knickelbein and W. J. C. Menezes, J. Phys. Chem. 96, 6611 (1992).

[16] C. T. Rettner and H. Stein, Phys. Rev. Lett. 59, 2768 (1987).

[17] A. Eichler and J. Hafner, Phys. Rev. Lett. 79, 4481 (1997).

[18] H. F. Busnengo, W. Dong and A. Salin, Phys. Rev. Lett. 93, 236103 (2004).

[19] S. C. Richtsmeier, E. K. Parks, K. Liu, L. G. Pobo and S. J. Riley, J. Chem. Phys. 82, 3659 (1985).

[20] A. Bérces, P. A. Hackett, L. Lian, S. A. Mitchell and D. M. Rayner, J. Chem. Phys. 108, 5476 (1998).

[21] C. Berg, T. Schindler, G. Niedner-Schatteburg and V. E. Bondybey, J. Chem. Phys. 102, 4870 (1995).

[22] T. H. Upton, Phys. Rev. Lett. 56, 2168 (1986). 
[23] T. H. Upton, D. M. Cox, A. Kaldor, Activation and Chemisorption of Hydrogen on Aluminum Clusters. In: P. Jena, B. K. Rao, S. N. Khanna (eds), Physics and Chemistry of Small Clusters. Springer, Boston (1987).

[24] A. Pramann and A. Nakajima, J. Chem. Phys. 115, 5404 (2001).

[25] N. X. Truong, M. Haertelt, B. K. Jaeger, S. Gewinner, W. chöllkopf, A. Fielicke and O. Dopfer, Int. J. Mass Spectrom. 395, 1 (2016).

[26] M. J. Frisch, G. W. Trucks, H. B. Schlegel, G. E. Scuseria, M. A. Robb, J. R. Cheeseman, G. Scalmani, V. Barone, G. A. Petersson, H. Nakatsuji, X. Li, M. Caricato, A. V. Marenich, J. Bloino, B. G. Janesko, R. Gomperts, B. Mennucci, H. P. Hratchian, J. V. Ortiz, A. F. Izmaylov, J. L. Sonnenberg, D. Williams-Young, F. Ding, F. Lipparini, F. Egidi, J. Goings, B. Peng, A. Petrone, T. Henderson, D. Ranasinghe, V. G. Zakrzewski, J. Gao, N. Rega, G. Zheng, W. Liang, M. Hada, M. Ehara, K. Toyota, R. Fukuda, J. Hasegawa, M. Ishida, T. Nakajima, Y. Honda, O. Kitao, H. Nakai, T. Vreven, K. Throssell, J. A. Montgomery, Jr., J. E. Peralta, F. Ogliaro, M. J. Bearpark, J. J. Heyd, E. N. Brothers, K. N. Kudin, V. N. Staroverov, T. A. Keith, R. Kobayashi, J. Normand, K. Raghavachari, A. P. Rendell, J. C. Burant, S. S. Iyengar, J. Tomasi, M. Cossi, J. M. Millam, M. Klene, C. Adamo, R. Cammi, J. W. Ochterski, R. L. Martin, K. Morokuma, O. Farkas, J. B. Foresman, and D. J. Fox, Gaussian, Inc., Wallingford CT, 2016.

[27] J. P. Perdew, K. Burke and M. Ernzerhof, Phys. Rev. Lett. 77, 3865 (1996).

[28] D. J. Henry, A. Varano and I. Yarovsky, Phys. Chem. A 112, 9835 (2008).

[29] J. Vanbuel, M.-y. Jia, P. Ferrari, S. Gewinner, W. Schöllkopf, M. T. Nguyen, A. Fielicke and E. Janssens, Top. Catal. 61, 62 (2018).

[30] J. Vanbuel, E. M. Fernández, M.-Y. Jia, P. Ferrari, W. Schöllkopf, L. C. Balbás, M. T. Nguyen, A. Fielicke and E. Janssens, Z. Phys. Chem. 233, 799 (2019).

[31] M. Jia, J. Vanbuel, P. Ferrari, W. Schöllkopf, A. Fielicke, M. T. Nguyen and E. Janssens, J. Phys. Chem. C 124, 7624 (2020).

[32] H. Wang, Y. Wang, J. Lv, Q. Li, L. Zhang and Y. Ma, Comput. Mater. Sci. 112, 406 (2016).

[33] F. Weigend and R. Ahlrichs, Phys. Chem. Chem. Phys. 7, 3297 (2005).

[34] S. Grimme, S. Ehrlich and L. Goerigk, J. Comput. Chem. 32, 1456 (2011).

[35] I. Mayer, J. Comput. Chem. 28, 204 (2007).

[36] M. Jia, J. Vanbuel, P. Ferrari, E. M. Fernández, S. Gewinner, W. Schöllkopf, M. T. Nguyen, A. Fielicke and E. Janssens, J. Phys. Chem. C 122, 18247 (2018).

[37] E. M. Fernández, A. Vega and L. C. Balbás, J. Chem. Phys. 139, 214305 (2013).

[38] V. T. Ngan, E. Janssens, P. Claes, A. Fielicke, M. T. Nguyen and P. Lievens, Phys. Chem. Chem. Phys. 17, 17584 (2015).

[39] Z. Jamshidi, K. Eskandari and S. M. Azami, Int. J. Quantum Chem. 113, 1981 (2013).

[40] S. Gilb, K. Jacobsen, D. Schooss, F. Furche, R. Ahlrichs and M. M. Kappes, J. Chem. Phys. 121, 4619 (2004). 
[41] F. Furche, R. Ahlrichs, P. Weis, C. Jacob, S. Gilb, T. Bierweiler and M. M. Kappes, J. Chem. Phys. 117, 6982 (2002).

[42] J. Lermé, P. Dugourd, R. R. Hudgins and M. F. Jarrold, Chem. Phys. Lett. 304, 19 (1999).

[43] M. F. Jarrold, J. E. Bower and J. S. Kraus, J. Chem. Phys. 86, p. 3876 (1987).

[44] S. Neukermans, E. Janssens, H. Tanaka, R. E. Silverans and P. Lievens, Phys. Rev. Lett. 90, 033401 (2003).

[45] B. K. Rao and P. Jena, J. Chem. Phys. 111, 1890 (1999).

[46] P. J. Roach, W. H. Woodward, A. C. Reber, S. N. Khanna and J. A. W. Castleman, hys. Rev. B 81, 195404 (2010).

[47] E. Janssens, S. Neukermans and P. Lievens, Curr. Opin. Solid State Mater. Sci. 8, 185 (2004). 


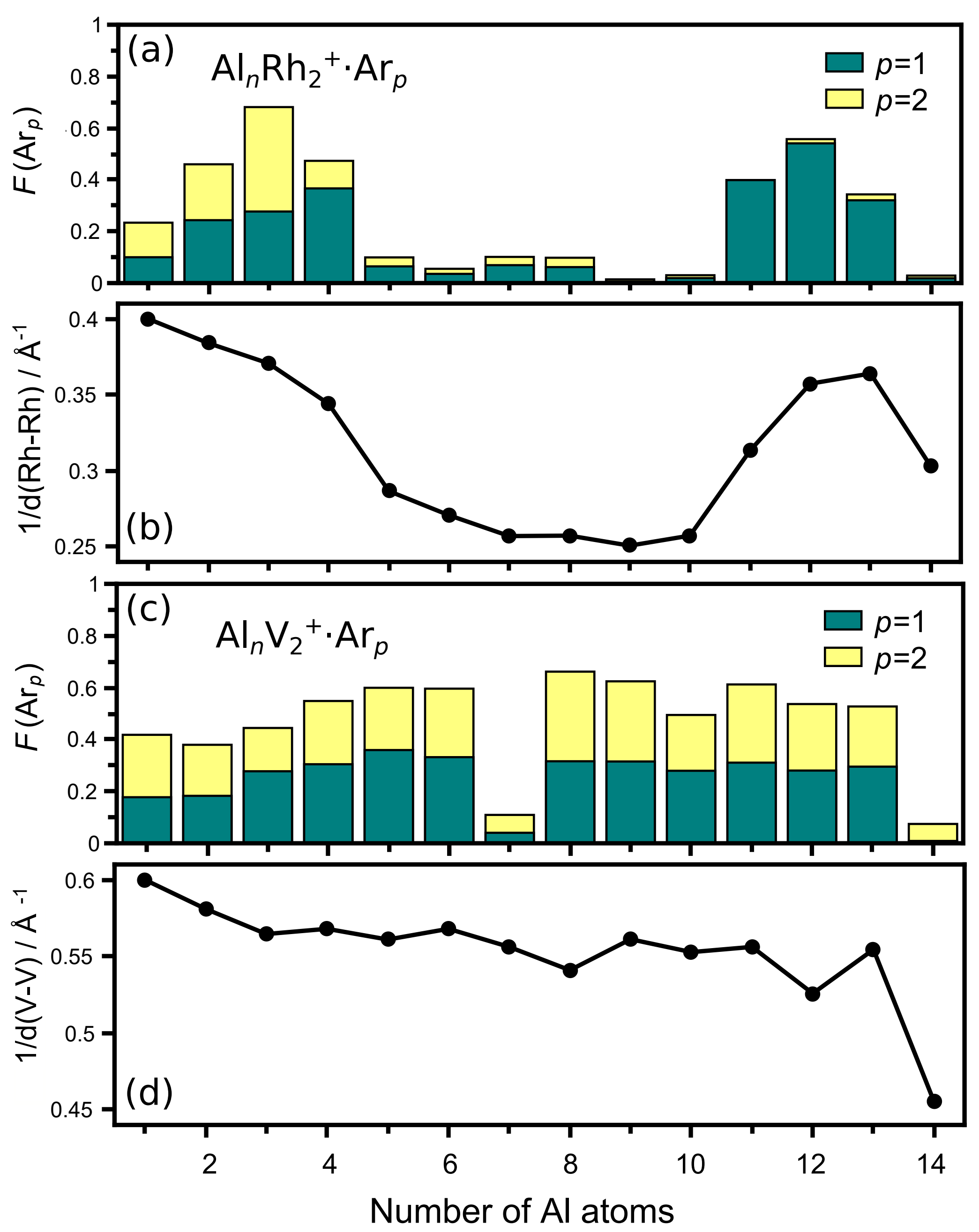



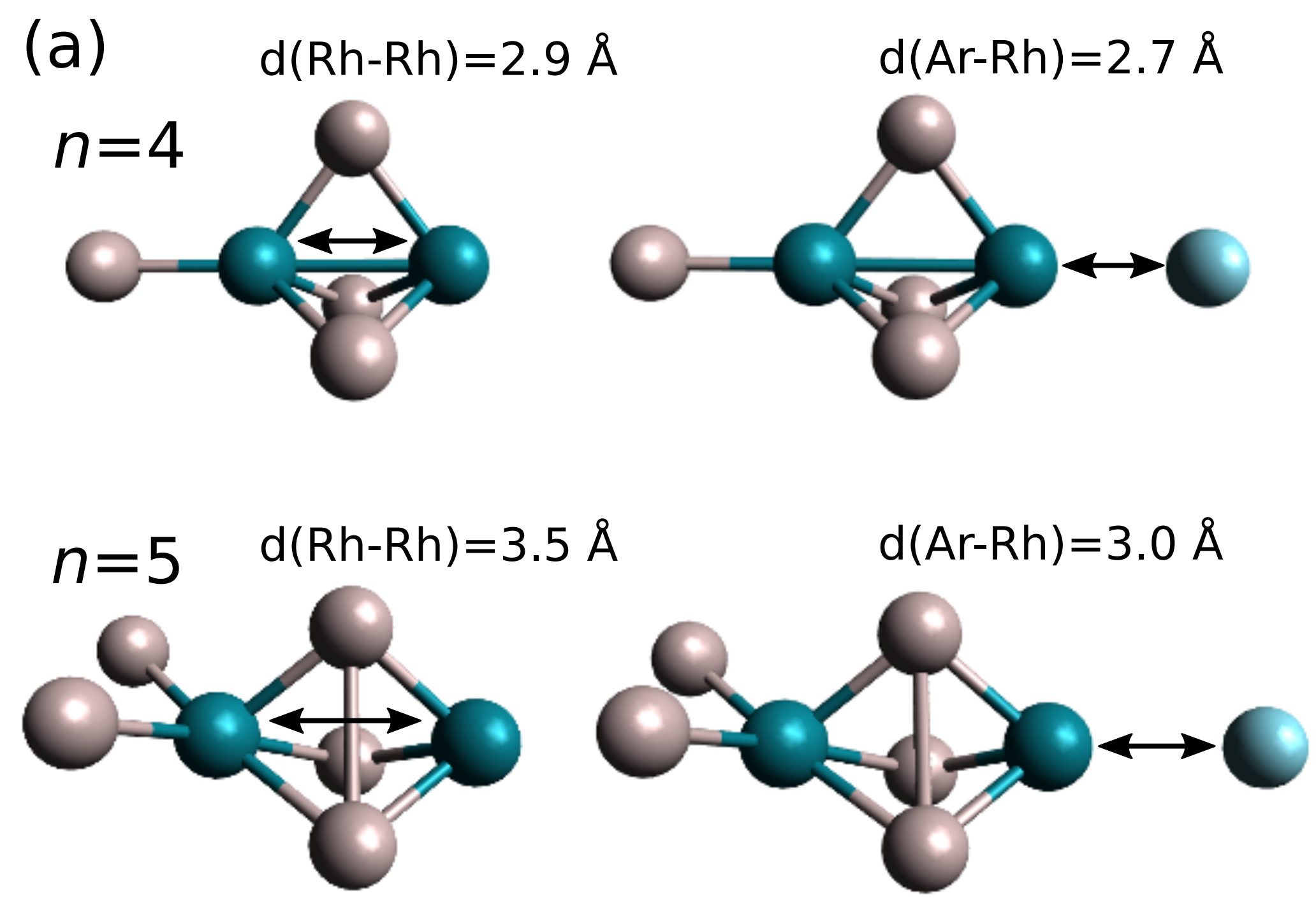

(b)
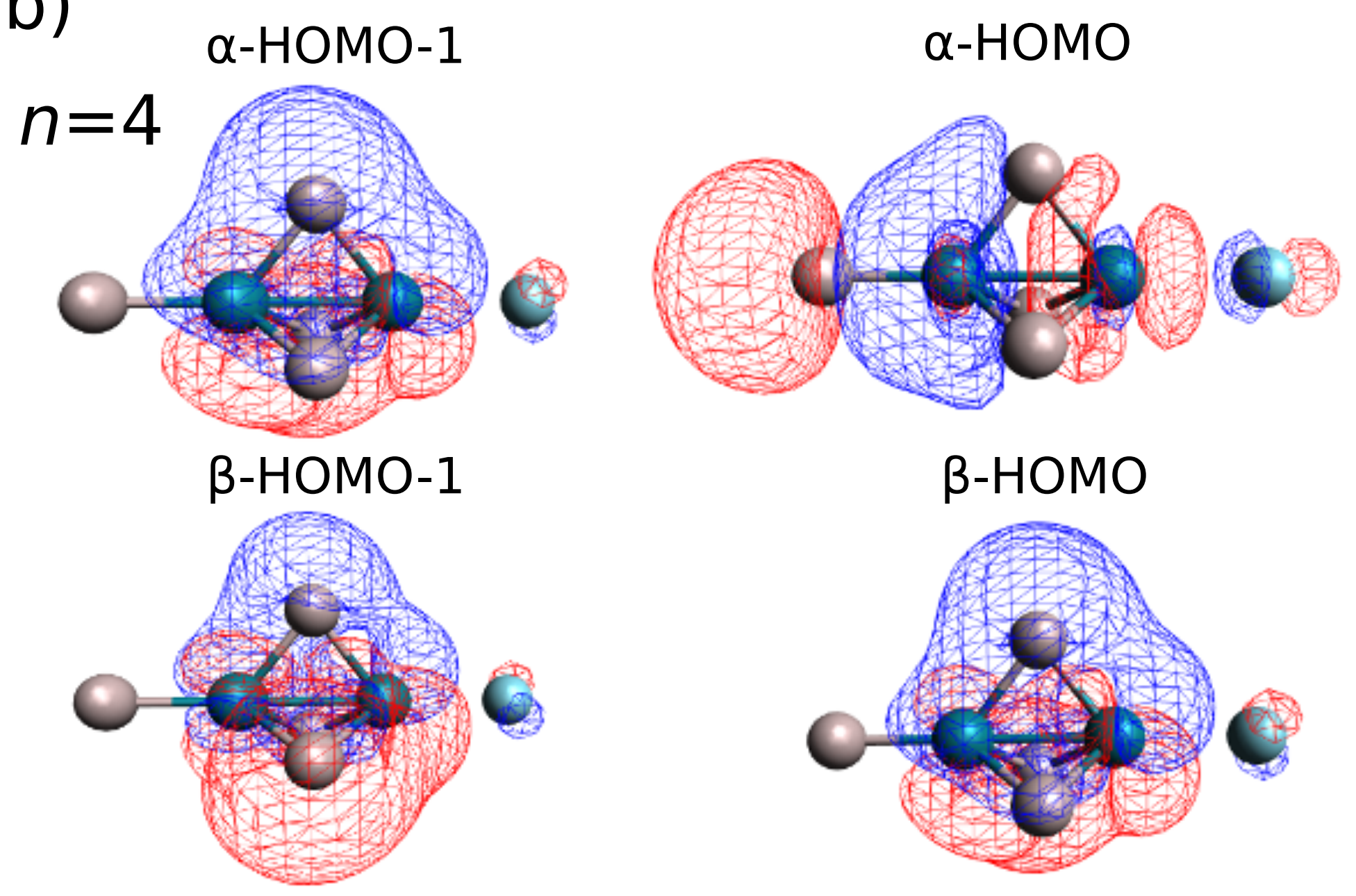

$n=5 \quad$ HOMO -1

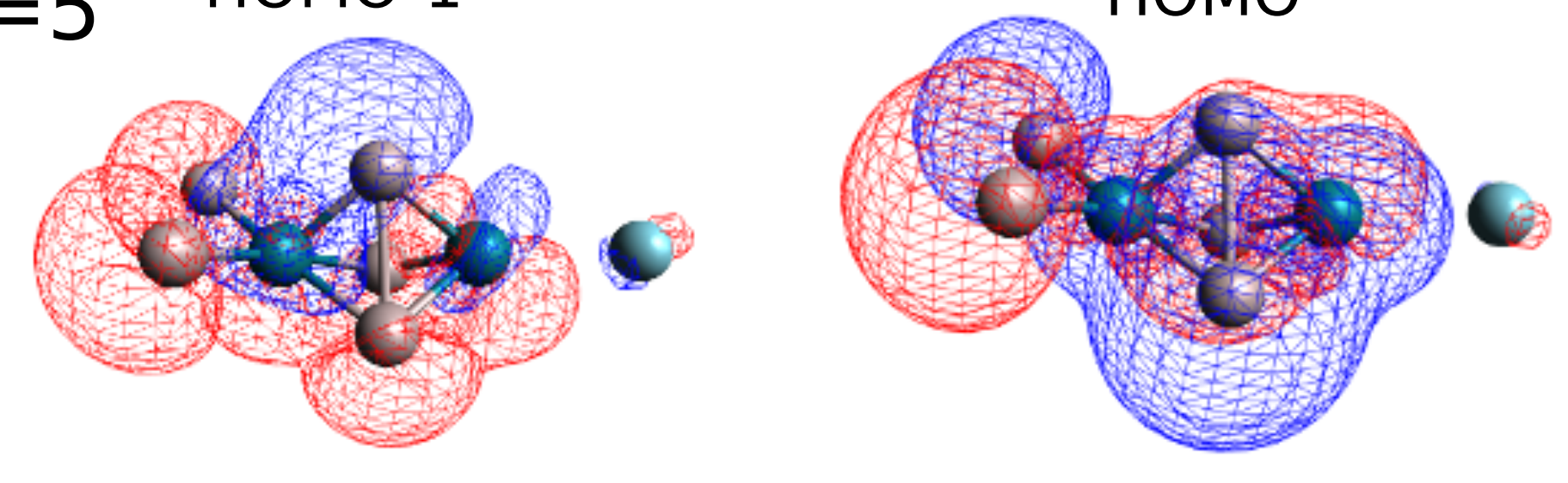

HOMO-2

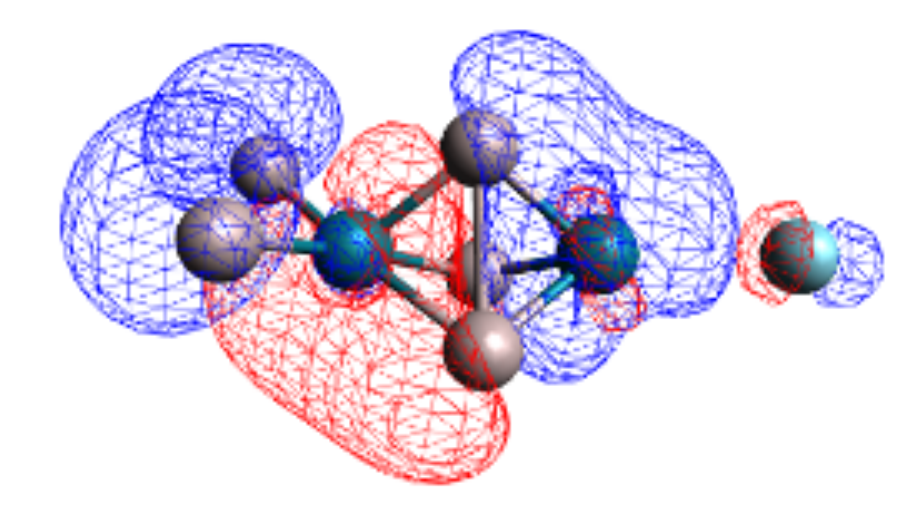




\section{$\alpha$-HOMO}

$$
\begin{aligned}
& d(A r-V)=2.75 \AA \\
& E_{B}(A r)=0.17 \mathrm{eV}
\end{aligned}
$$
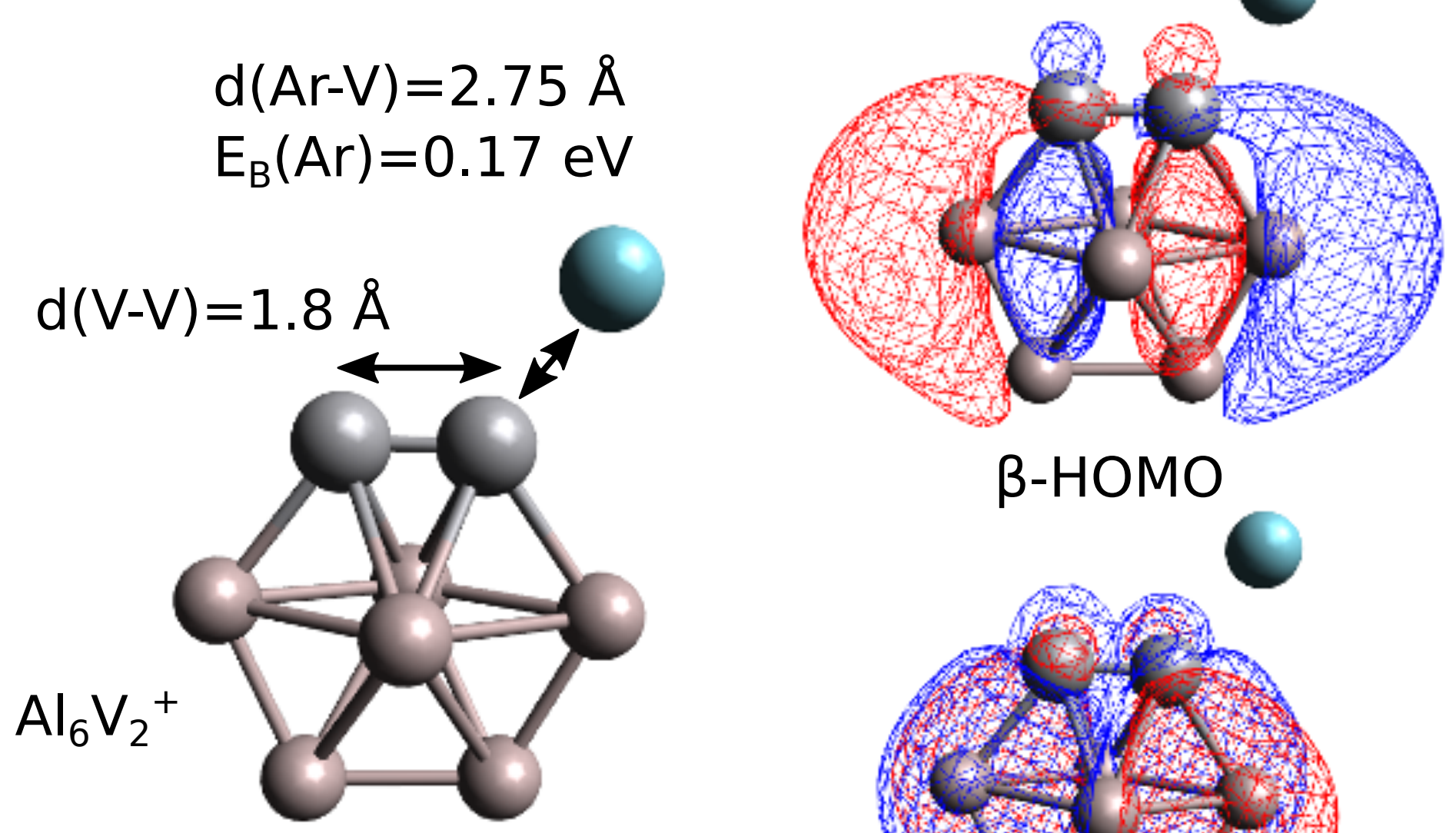

\section{$\beta-H O M O$}
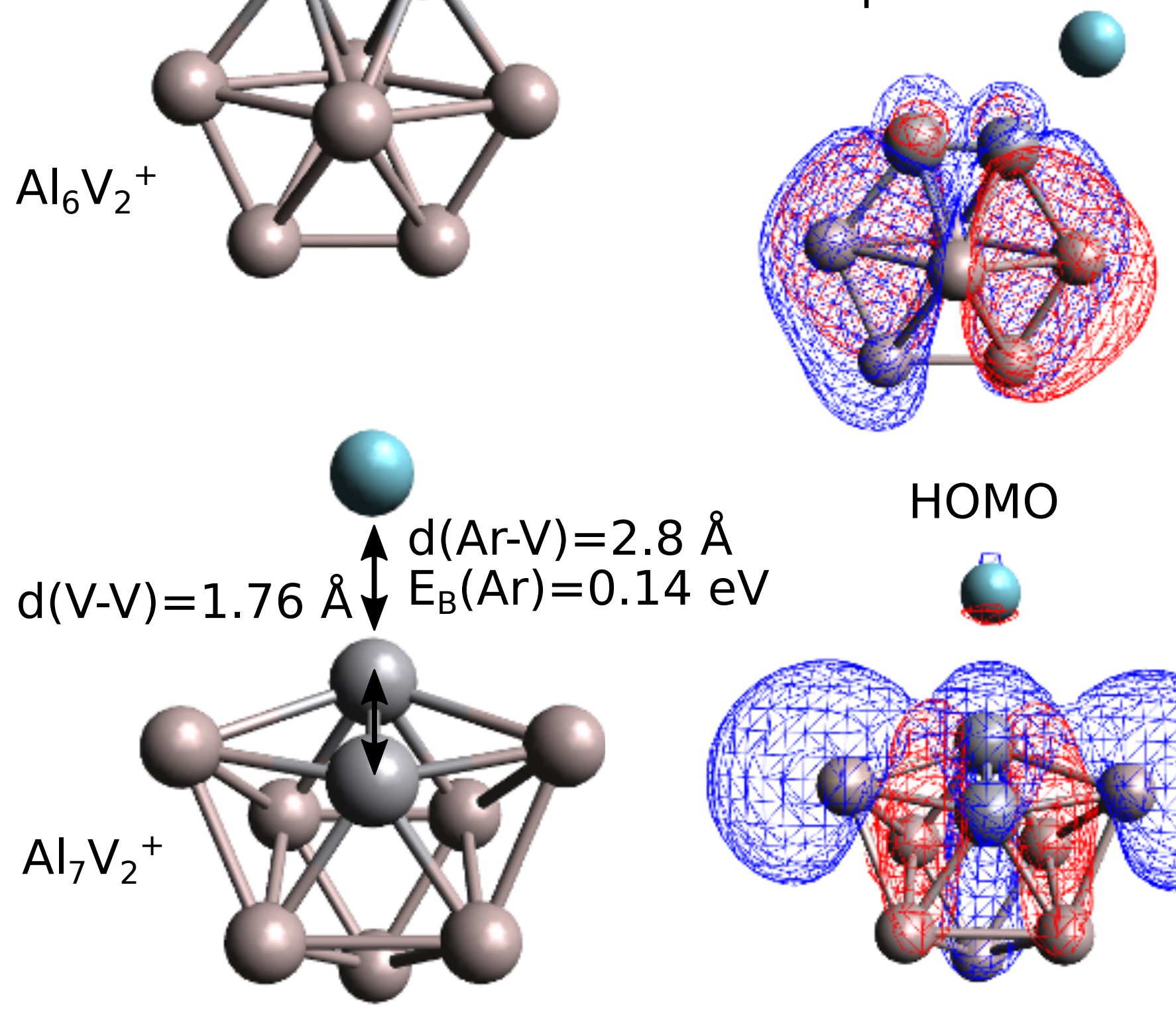

HOMO
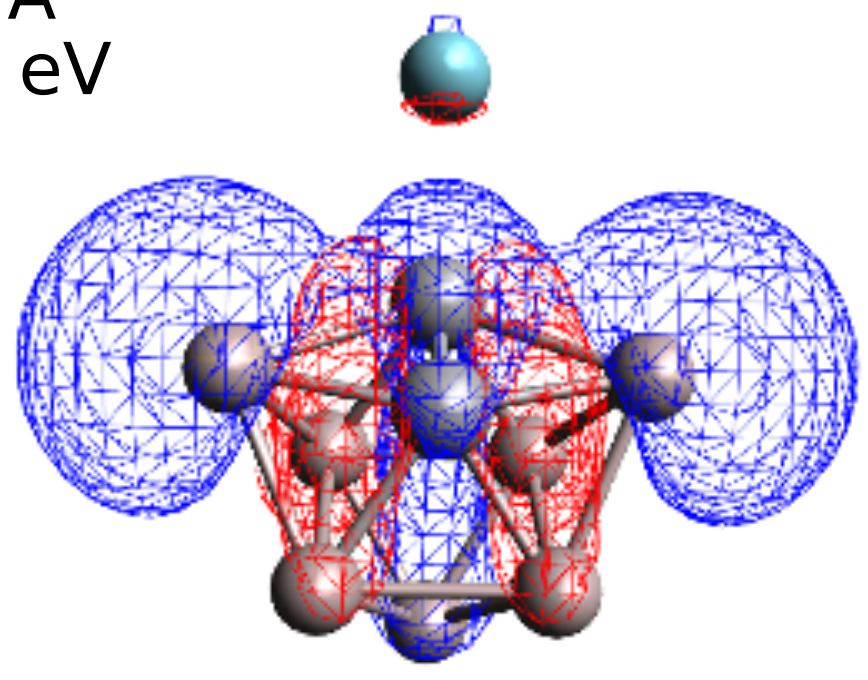
$\mathrm{Al}_{4} \mathrm{Rh}_{2}{ }^{+}$
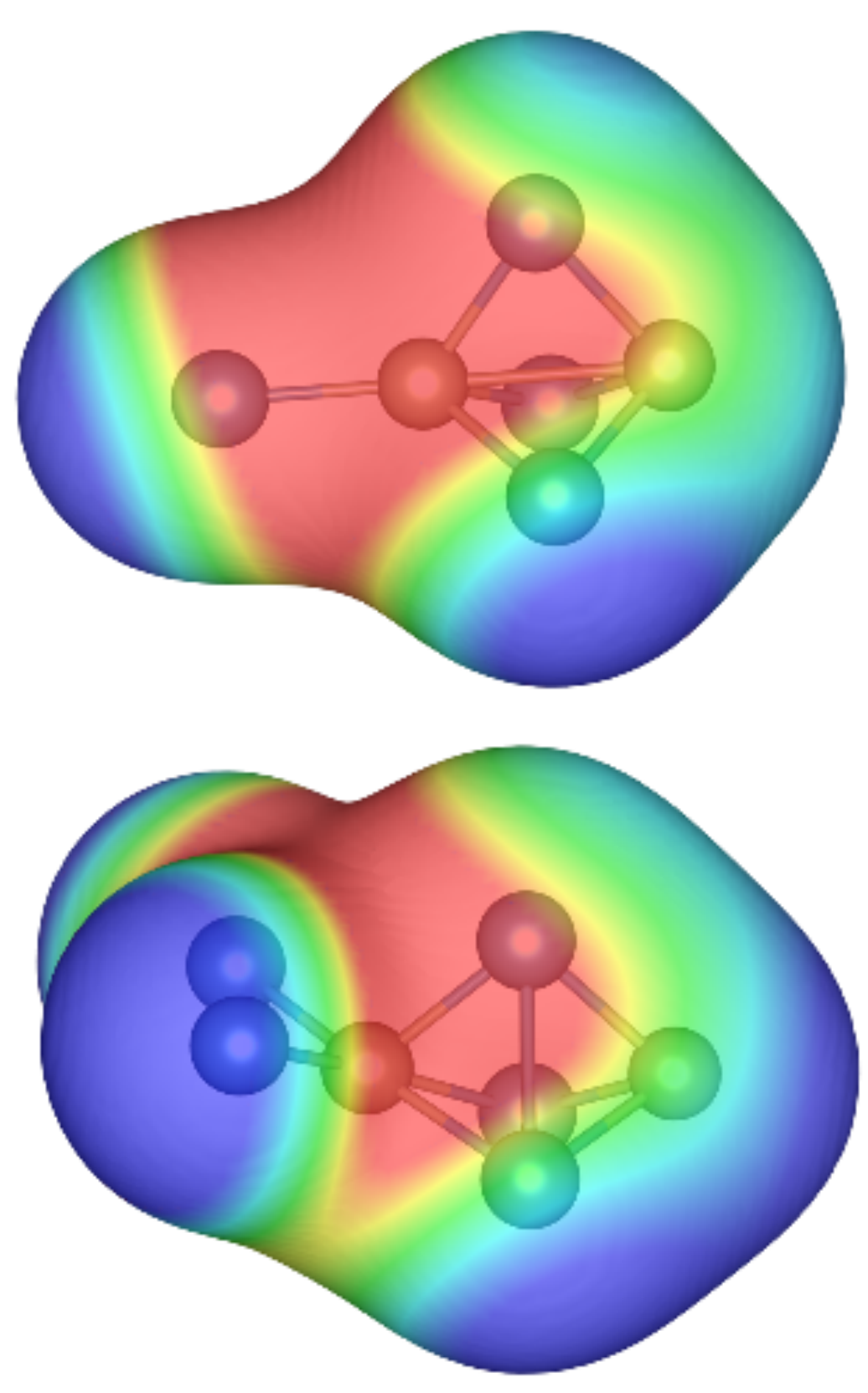

$\mathrm{Al}_{5} \mathrm{Rh}_{2}{ }^{+}$
$\mathrm{Al}_{6} \mathrm{~V}_{2}{ }^{+}$
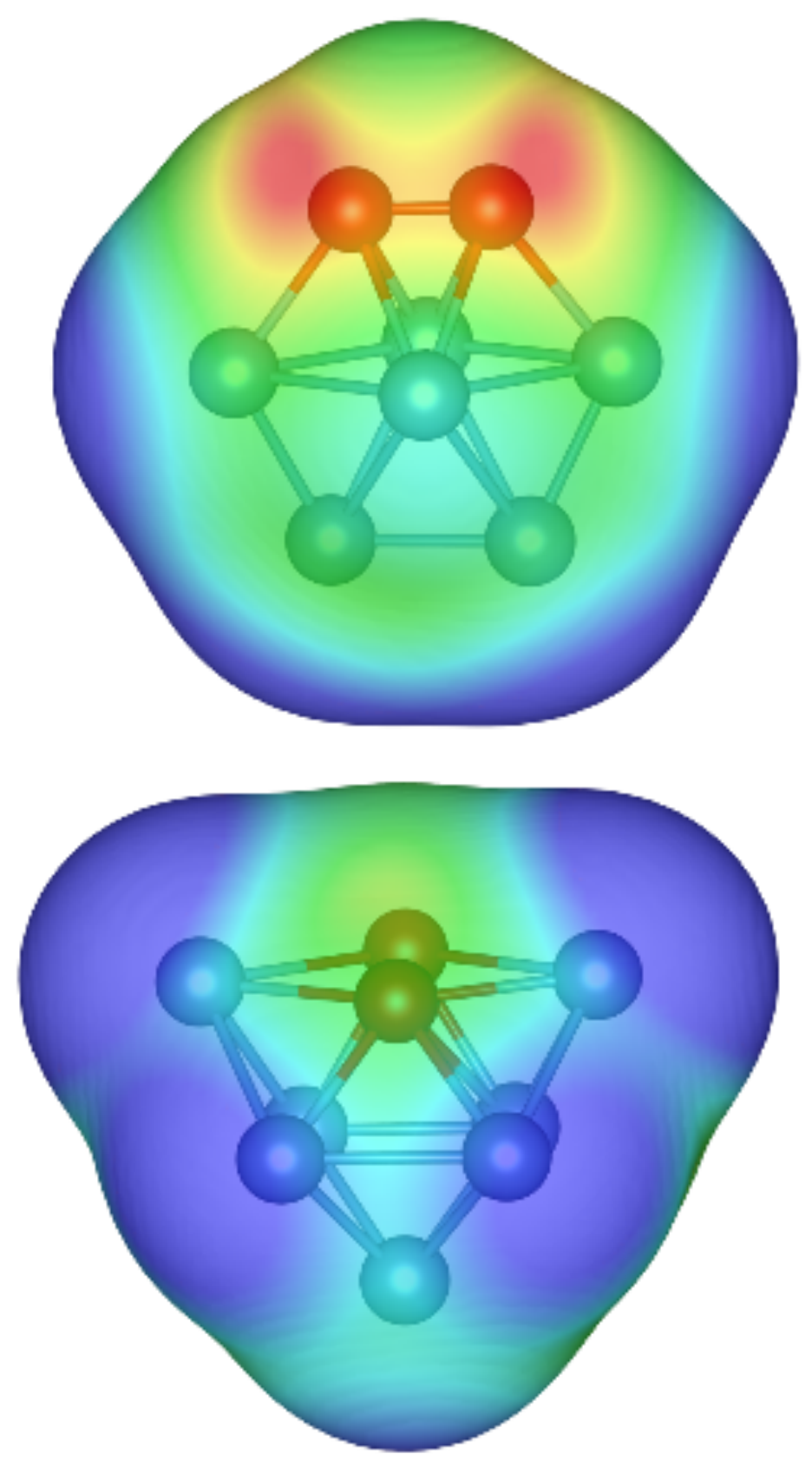

$\mathrm{Al}_{7} \mathrm{~V}_{2}{ }^{+}$
0.09 Ry

0.07 Ry 


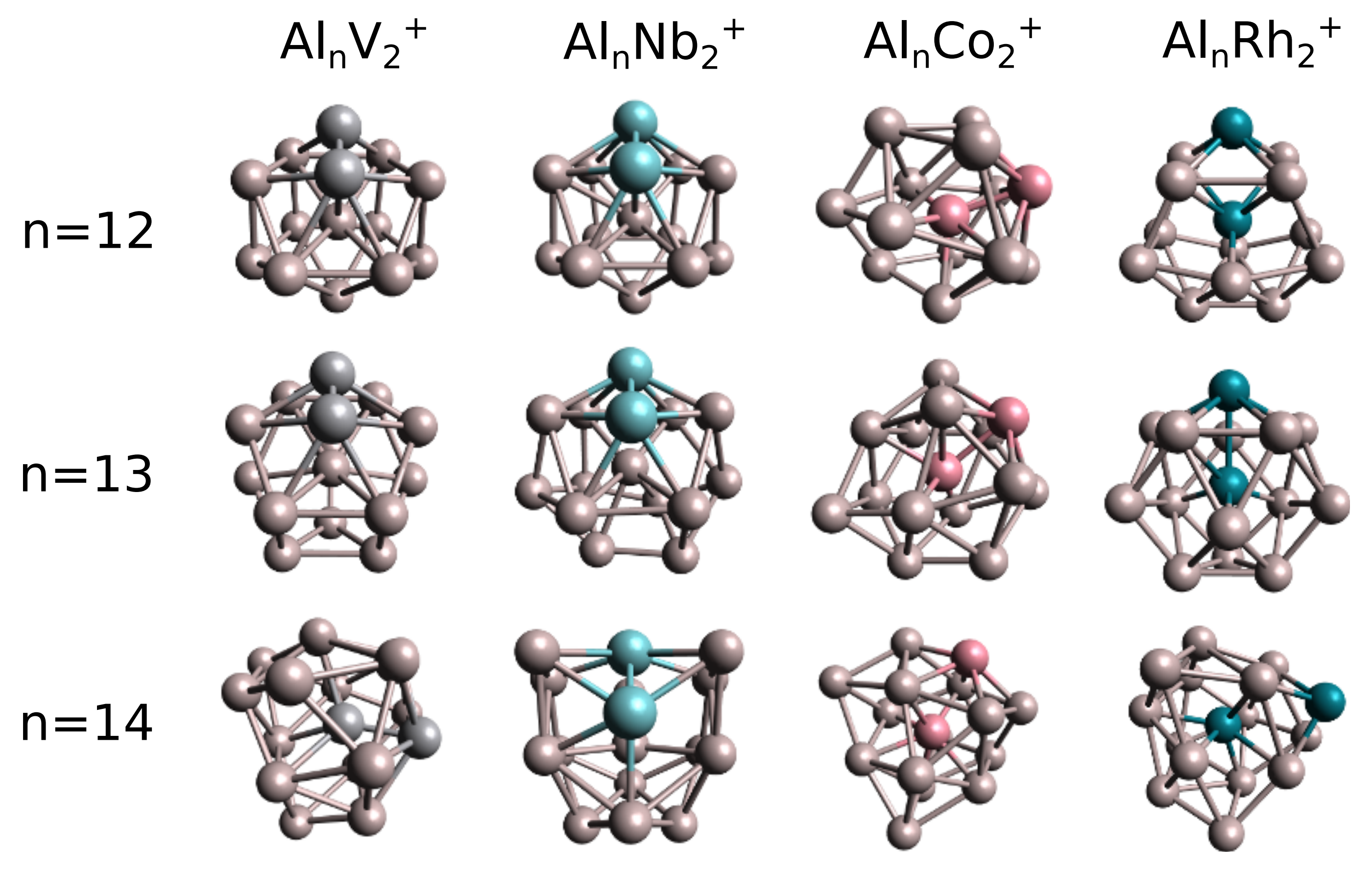




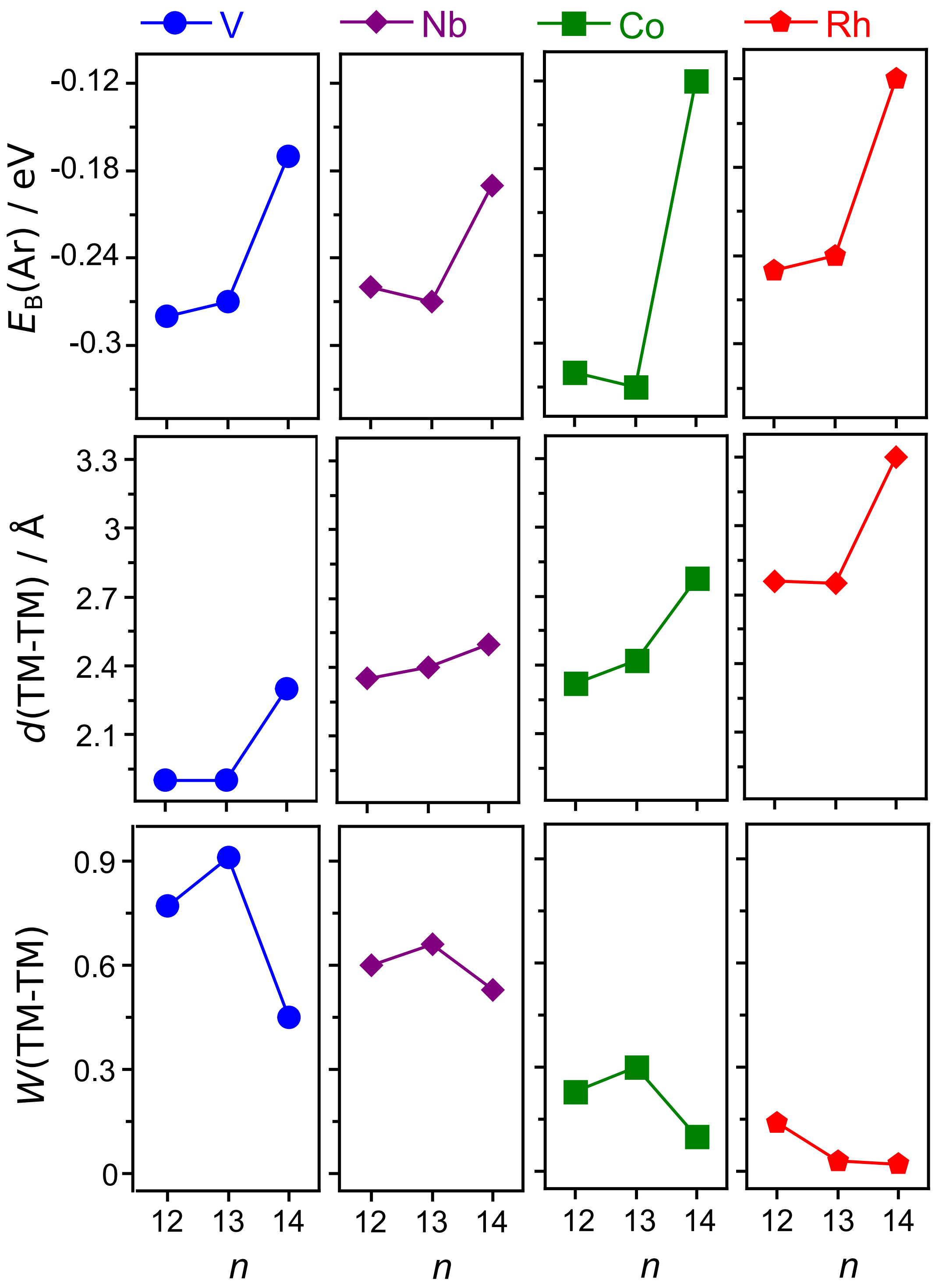




\section{$n=13$}

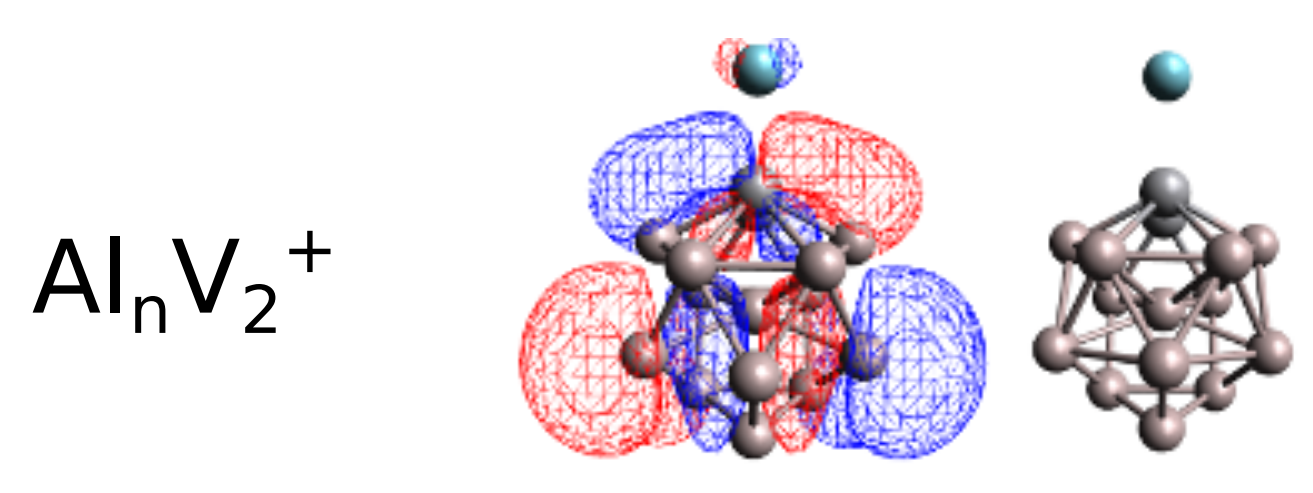

$$
\mathrm{Al}_{\mathrm{n}} \mathrm{Nb}_{2}{ }^{+}
$$
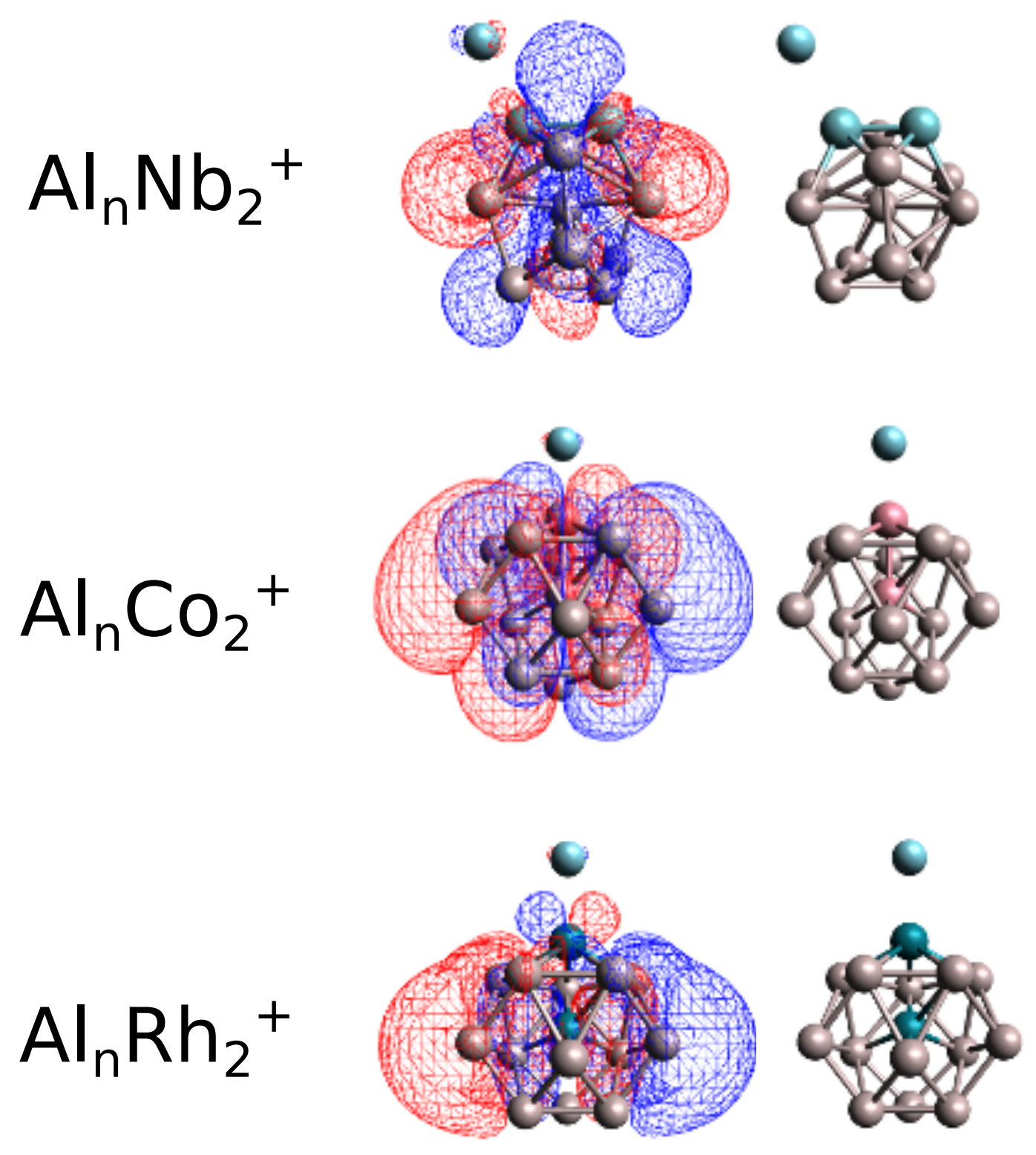

$n=14$
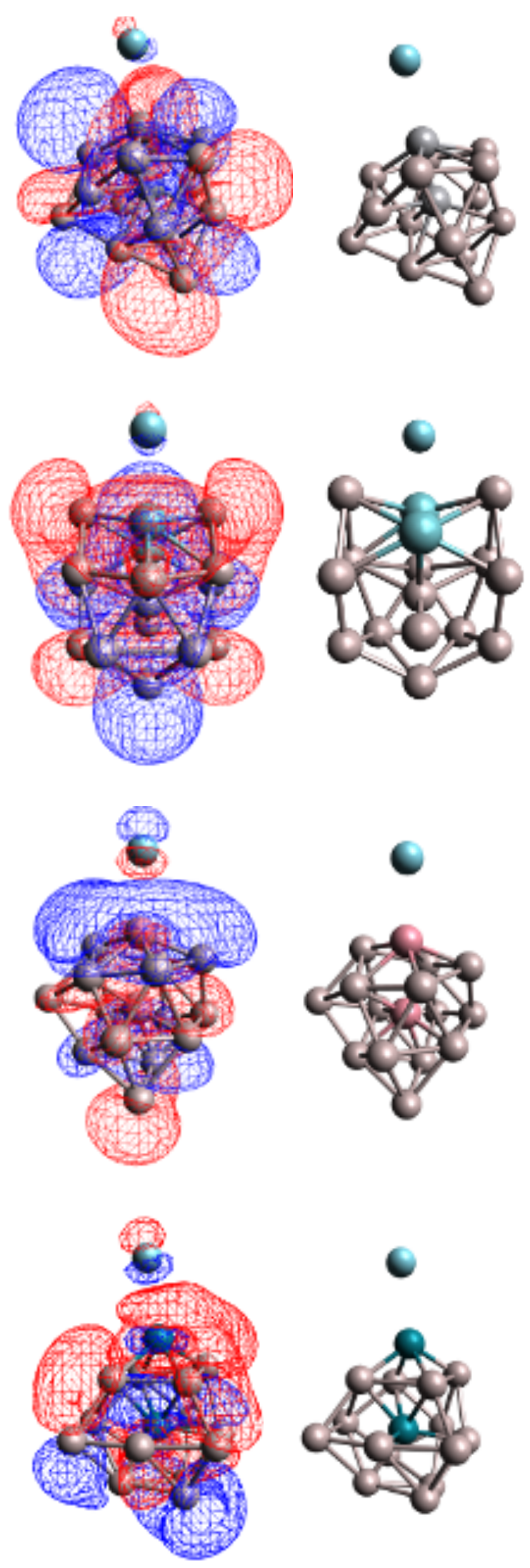
